\title{
An analysis of manufacturer benefits under vendor-managed systems
}

\author{
SEÇIL SAVAŞANERIL ${ }^{1}$ and NESIM ERKIP ${ }^{2, *}$ \\ ${ }^{1}$ Department of Industrial Engineering, Middle East Technical University, 06531 Ankara, Turkey \\ E-mail:secil@ie.metu.edu.tr \\ ${ }^{2}$ Department of Industrial Engineering, Bilkent University, 06800 Bilkent, Ankara, Turkey \\ E-mail:nesim@bilkent.edu.tr
}

Received February 2008 and accepted October 2009

\begin{abstract}
Vendor-Managed Inventory (VMI) has attracted a lot of attention due to its benefits such as fewer stock-outs, higher sales, and lower inventory levels at the retailers. Vendor-Managed Availability (VMA) is an improvement that exploits the advantages beyond VMI. This article analyzes the benefits beyond information sharing and assesses the motivation for the manufacturer (vendor) behind joining such a program. It is shown that such vendor-managed systems provide increased flexibility in manufacturer's operations and may bring additional benefits. An analysis is presented on how the system parameters affect the profitability and determine the conditions that make the vendor-managed system a viable strategy for the manufacturer.
\end{abstract}

Keywords: Vertical collaboration, vendor-managed inventory, capacity management, operational flexibility, consignment stock

\section{Introduction}

Vendor-Managed Inventory (VMI) is a collaborative process between a supplier/manufacturer and a manufacturer/retailer/distributor, where the manufacturer gains access to the demand and inventory information at the retailer and uses this information to "better" manage the retailer's inventory. VMI started as a pilot program in the retail industry between Procter\&Gamble and WalMart in the 1980s and resulted in significant benefits, such as lower inventory levels, fewer stock-outs, and increased sales, and has been adopted by many other supply chains such as those of Dell, Barilla, and Nestle. In many research and business articles, the benefits of VMI are attributed to information sharing between the manufacturer and the retailer (see, for example, Cachon and Fisher (1997) and Schenck and McInerney (1998)). However, there is more to VMI than just the information availability; there are benefits hidden in the increased flexibility of the manufacturer's production operations. There exists limited analytical work in the literature on how the manufacturer can translate this flexibility into benefit and why the parties join a VMI program. We believe that it is important to emphasize the benefits of VMI additional to information sharing, so that the motivation behind joining a VMI program is better comprehended.

${ }^{*}$ Corresponding author
In a vendor-managed setting, although the manufacturer takes control of inventory, it is the retailer that usually benefits from the manufacturer managing the inventory (Dong and $\mathrm{Xu}, 2002$ ). The reason for this is that the retailer can always set the terms of the agreement such that the performance measures (such as number of stock-outs, average inventory level, etc.) will improve. Whether the manufacturer benefits from the vendor-managed system, on the other hand, depends on how well the manufacturer can take advantage of the increased flexibility. In the agreement, the retailer may reflect a required product availability on the shelf or service level by imposing a lower bound on the inventory level. Similarly, due to shelf space constraints or to avoid high inventory levels, the retailer may limit the amount of replenishment from the manufacturer. Therefore, a contract may consist of an upper and a lower bound on inventory level, where overshooting or undershooting by the manufacturer is penalized. While penalties compel the manufacturer to conform with the inventory limits, it is definitely a challenging task for the retailer to determine the penalties as well as to set the bounds on the inventory level that will result in the desired service level or inventory holding cost.

Our modeling of VMI is closer to Vendor-Managed Availability (VMA) (Hausman, 2003), where the vendor is more flexible in terms of replenishment operations than VMI, since in VMI, replenishments are more restricted due to the bounds on the retailer's inventory level. VMA has 
been practiced by several major retailers such as J.C. Penney and Costco. J.C. Penney sources shirts from a Hong Kong-based shirt maker and this supplier completely controls the inventory by monitoring J.C. Penney's stock levels and makes replenishments directly to the store, if necessary. To ensure availability, at times the supplier expedites the delivery by air-shipping (Kahn, 2002; Hausman, 2003). Similarly, Kimberly-Clark, a supplier of products such as diapers, tissues, and paper towels for Costco in the United States, is very flexible in its replenishment operations. The company simply "keeps each (Costco) store's inventory as low as possible without risking empty shelves" (Nelson and Zimmerman, 2000). These examples describe more flexible agreement terms between the manufacturer and the retailer. To reflect this practice, in our vendor-managed model we assume that the service level is the only constraint for the manufacturer, which results in an increased flexibility even compared to VMI. For instance, at times the manufacturer may not prefer to replenish a retailer's stock if the capacity can be used for a more profitable order. At other times when there is excess capacity, i.e., when the capacity is less valuable, several replenishments may enable an increased service level at the retailer. The retailer ends up with the same service level, whereas the manufacturer effectively manages its production, capacity allocation, and replenishment operations. In this article, we consider the notions introduced by VMA, an enhanced version of VMI. In the rest of this article, we use the terms VMA or vendor-managed system to represent this enhanced version of VMI.

In this study, we model a supply chain consisting of a single manufacturer and a retailer. We first define the traditional system under which the manufacturer and the retailer operate and then introduce the vendor-managed system and compare the two systems. We assume that the retailer sets the terms of the contract such that she is never worse off under the new (vendor-managed) system. We make the analysis from the perspective of the manufacturer who carries most of the collaboration burden. The retailer faces stochastic demand and in the traditional system periodically places orders to the manufacturer. The manufacturer has limited capacity to meet the orders from the retailer and a more expensive outsourcing option. To analyze the benefits due to the vendor-managed system alone, our proposed model for the traditional system considers a manufacturer that has full information on end-demand distribution, demand realization, and inventory levels at the retailer and hence revisits capacity planning aspects of operating a traditional manufacturing system. We assume that the parties do not share cost information. Furthermore, information on available capacity or end-of-period inventory level at the manufacturer is not shared with the retailer. Our focus is on the vertical collaboration process in the supply chain under this asymmetric and partially shared information setting.

In vendor-managed systems the issue of who owns the inventory depends on the relationship between the manufacturer (supplier) and the retailer (manufacturer). If the manufacturer is very powerful (such as Dell) it may force the suppliers to own the inventory at the manufacturer's site or at a supply hub nearby. On the other hand, if the supplier is powerful, then inventory may not be consigned. Intel, for instance, although it has an agreement with Dell, does not operate through a supply hub as do other suppliers (Barnes et al., 2000). We consider two types of vendor-managed agreements, consignment stock and no-consignment stock, and for each type analyze how the manufacturer may benefit from managing the retailer's inventory. In our model there does not exist an upper and lower bound restriction at the retailer's inventory level; however, the retailer explicitly specifies service level and average inventory level requirements. Given this setting we address the following questions.

1. Are there any benefits for the manufacturer in managing the retailer's inventory apart from what is already achieved by sharing demand and inventory information?

2. What are the conditions that make the manufacturer better off under the vendor-managed system considered?

3 . Under the vendor-managed system should the manufacturer consign the stock or not?

Our work contributes to the literature in several ways. Our work is one of the few studies that analyzes benefits due to vendor-managed systems from the manufacturer's perspective and that identifies the conditions to make the manufacturer willing to join such an agreement. Earlier studies either ignore the motivation behind vendor-managed systems or focus only on total supply chain benefits rather than the individuals' benefits. Furthermore, we make a comparison of benefits under consignment stock and noconsignment stock models to determine the type of agreement under which the manufacturer will benefit, whereas the previous literature mostly assumes centralized consignment stock models.

The remainder of the article is organized as follows. In Section 2 we review the previous work on vendor-managed inventory systems. In Sections 3 and 4 the model characteristics and structural properties are presented. In Section 5 we make an experimental analysis and discuss the results, and based on these discussions we provide managerial insights. We present our conclusions in Section 6 .

\section{Literature review}

The majority of existing studies analyze the vendormanaged system in a manufacturer-retailer setting, while a few consider a supplier-manufacturer setting (Choi et al., 2004). Inventory ownership is modeled either by totally consigned stock or by the transfer of the title at the time of arrival. In most of the previous studies, the focus of the analysis is limited to designing an optimal operating policy for the vendor in a vendor-managed system, and the motivation of the vendor in managing the inventory is not under consideration. 
In the analysis of the vendor-managed systems under a single manufacturer and multiple retailers, the focus is mainly on the savings in transportation due to better order consolidation or savings due to coordination of retailer replenishments. To analyze the benefit of VMI, Cetinkaya and Lee (2000) compare a VMI system with a traditional system. In the traditional system the manufacturer sends a shipment immediately when the demand arrives, whereas in a VMI system shipments are consolidated. The authors determine the optimal dispatch quantity under VMI considering the inventory cost and the transportation cost incurred by the manufacturer and conclude that when inventory holding cost and dispatching cost are low, VMI results in significant savings for the manufacturer. Kleywegt et al. (2002) study an inventory routing problem of a manufacturer who owns the inventory at the retailers. An approximation method is developed to find the minimum-cost routing policy; however, there is no discussion on whether the manufacturer is better off under the vendor-managed system. Waller et al. (1999) also consider a multiple retailer setting and through a simulation analysis demonstrate the effects of VMI on the inventory levels at the retailers and on the capacity utilization at the manufacturer. VMI results in savings due a decrease in the inventory levels, which is a consequence of the increased frequency of retailer replenishments. Aviv and Federgruen (1998) consider a capacitated supplier with multiple retailers and analyze how coordination of retailer orders under VMI decreases the system-wide cost of operation. They explicitly model a traditional system with no information sharing and with full information sharing to assess the benefits of VMI beyond information sharing.

Fry et al. (2001) compare a VMI system with a traditional system in a single manufacturer, single retailer setting under full information sharing. The authors identify the optimal operating policies of both the manufacturer and the retailer in a stochastic setting. Under VMI the retailer determines the maximum inventory level and the vendor incurs a penalty if the inventory level is outside the limits. The authors find that VMI performs close to a centralized model in the presence of high demand variance and high cost of outsourcing. Several other papers study the optimal decisions of the manufacturer under VMI in a deterministic environment. Valentini and Zavanella (2003) and Shah and Goh (2006) consider a consignment stock system where the demand is deterministic with a constant rate. Jaruphongsa et al. (2004) study a problem with delivery time windows and early shipment penalties under dynamic demand. The authors propose a dynamic programming algorithm to obtain the minimum cost under VMI.

Depending on the form of agreement between the retailers and the manufacturer, the system under a vendormanaged regime can be very close to a centralized system. A number of papers analyze the role of VMI as a channel coordinator. Bernstein et al. (2006) study the constant wholesale price and quantity discount contracts that lead to perfect coordination in a supply chain with multiple competing retailers and show how VMI helps achieve the coordination. Nagarajan and Rajagopalan (2008) show that simple contracts in VMI can improve the performance of the overall system under certain conditions. Dong and Xu (2002) analyze the benefits of VMI both in terms of total channel cost and vendor's cost. In their model the retailers set the purchasing price in the contract and the supplier, in turn, determines the selling quantity. The authors determine the conditions under which the supplier benefits from VMI and conclude that VMI can always decrease the cost of channel as a whole. Fry et al. (2001) also discuss centralization of the supply chain.

There are only a few works on the service-level considerations in a VMI system. In most of the papers the service level is implicitly assumed in the lower inventory level set by the lower echelon. Choi et al. (2004) study the servicelevel relationship between a supplier and a manufacturer in a VMI framework and show that high service levels at the supplier do not guarantee the desired service level at the manufacturer and that expected backorders should also be taken into account.

Our study is most closely related to Fry et al. (2001). We study a single-manufacturer, single-retailer system and compare the vendor-managed system with the traditional system to quantify the benefits beyond information sharing. However, we focus on the benefits to the manufacturer to determine the motivation to make an agreement. We furthermore consider capacity management as an important factor in determining the benefits of vendor-managed systems. Additionally, we study both consignment and noconsignment models to identify the conditions that make either model beneficial for the manufacturer. In our model, we do not necessarily regard the vendor-managed system as a coordinated system. We propose a more realistic setting with asymmetric and partial information sharing and focus on the collaboration process. Since usually it is the manufacturer that is reluctant in these agreements, we analyze the problem from the manufacturer's perspective. Finally, we take service level considerations explicitly into account.

In summary, our model differs from the existing studies in the following aspects.

1. We look at manufacturer benefits in joining to the vendor-managed system.

2. We identify the benefits beyond information sharing to clearly assess the manufacturer's motivation.

3. We explicitly model the consignment and noconsignment systems and provide a comparison of these systems to determine which type of agreement is more beneficial to the manufacturer. In practice, if the lower echelon is more powerful, the stock is usually consigned by the manufacturer. Otherwise, if the manufacturer is powerful, the stock is not necessarily consigned. Therefore, it is not apparent whether or not the manufacturer should consign the stock. 
4. Finally, we analyze how benefits under a vendormanaged system change with system parameters. Specifically, we measure the effect of capacity management and provide a detailed analysis of the benefits from production and transportation flexibility.

\section{A modeling framework for the manufacturer}

We compare two settings: a traditional system where the retailer manages and owns the inventory, and a vendormanaged system. In the vendor-managed system we model two cases based on the ownership of stock. Under the noconsignment stock model (VM-NC), the stock is managed by the manufacturer while owned by the retailer. Under the consignment stock model (VM-C), the inventory is both managed and owned by the manufacturer. We assume the retailer accepts the agreement only if the performance measures are as good compared to the traditional case.

We consider a periodic-review model where the manufacturer has limited and non-stationary capacity, which is known by the manufacturer in advance. The nonstationarity in the capacity reflects an environment where the manufacturer has several customers and allocates some portion of the capacity to the retailer and the remaining to the other orders. We assume that the capacity allocated to the retailer may be zero in some periods, i.e., the manufacturer produces for the retailer in every $T_{\mathrm{p}}$ periods, and without loss of generality we assume non-negative capacity in the first period of $T_{\mathrm{p}}$. We call the time span between two positive capacity levels as the production cycle. Note that the cyclic production concept is a well-known and utilized idea in the literature. Maxwell and Muckstadt (1985) were the first to introduce the idea of consistent and realistic reorder intervals. Li and Wang (2007) mention cyclic structures within the supply chain as a coordination mechanism. Fry et al. (2001) consider a similar cyclic structure in their study. We further assume that the level of capacity may be nonstationary for the periods in which the manufacturer produces for the retailer. We assume this non-stationarity also shows a cyclic behavior. In other words, in every $T_{\mathrm{m}}$ periods the level of the capacity is the same and $T_{\mathrm{m}}$ may consist of several $T_{\mathrm{p}}$ cycles, each cycle with possibly a different capacity level (see Fig. 1). We call this larger cycle the capacity cycle. Similarly, due to scheduling practices the retailer places a replenishment order to the manufacturer in every $T_{\mathrm{r}}$ periods. We call the retailer's cycle the replenishment cycle.

We assume that the replenishment orders are quantized, where the replenishment size $Q$ reflects economies of scale in manufacturing and transportation and is an agreed-upon quantity between the manufacturer and the retailer. Note that this assumption implies that the manufacturer is expected to operate with this "bucket" size $Q$ with all of the customers. Hence, we can assume that the capacity at the manufacturer is a non-negative integer multiple of $Q$. This type of environment can be ob-

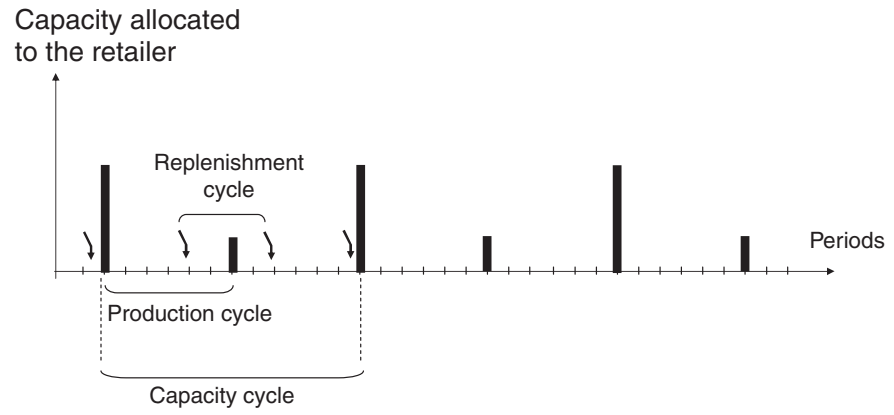

Fig. 1. The manufacturer's capacity cycle is 12 periods, the production cycle is 6 periods, and the retailer's replenishment cycle is 4 periods.

served in practice. For example, DMC, a French thread company, lowered its shipment size from 24-unit cases to 12-unit cases after an agreement made with WalMart. Since switching to a 12-unit case required significant investment, the company is now shipping in 12-unit cases to all of its customers (Fishman, 2006).

The end-item demand is stochastic and stationary. Holding cost is incurred based on end-of-period inventory level, and the retailer operates based on a service level constraint. Excess demand at the retailer can be backlogged (there is no cost associated); however, the manufacturer (always) meets the retailer's order either through regular stock or by subcontracting (for a similar usage of subcontracting option, see, Gavirneni et al., 1999). Here, the term subcontracting actually corresponds to a variety of alternatives to meet the unsatisfied demand. The manufacturer can use an additional "setup" from the capacity of other products/customers, make overtime production, expedite the supply, or let the retailer take care of unmet demand but pay an (implied) penalty. We assume that transportation time is negligible and hence the produced amount is delivered at the same period (overnight). Note that this is consistent with the just-in-time delivery concept.

We model the retailer's and the manufacturer's problem under the traditional system and the manufacturer's problem under the vendor-managed system as a Markov Decision Process (MDP). We determine the optimal operating policy under each system. Model parameters, decision variables, and state variables are presented in Table 1.

One of the objectives of this study is to quantify the benefits of the vendor-managed system for the manufacturer when demand and inventory information of the retailer is available. Specifically, we make the following assumptions on information sharing.

1. The information of periodic demand realization, endof-period inventory level at the retailer, and retailer's demand distribution is provided by the retailer to the manufacturer.

2. Information of unit inventory holding cost or any other cost information at the retailer is not shared with 
Table 1. Notation for traditional and vendor-managed system models

\begin{tabular}{|c|c|}
\hline \multicolumn{2}{|c|}{ Parameters } \\
\hline$T_{\mathrm{p}}:$ & length of the production cycle for the manufacturer \\
\hline$T_{\mathrm{m}}:$ & length of the capacity cycle for the manufacturer \\
\hline$T_{\mathrm{r}}:$ & $\begin{array}{l}\text { length of the replenishment cycle for the retailer under } \\
\text { traditional system }\end{array}$ \\
\hline$D_{i}:$ & $\begin{array}{l}\text { random variable denoting demand over } i \text { periods, } \\
\qquad i \in\left\{1, \ldots, T_{\mathrm{r}}\right\}\end{array}$ \\
\hline$P_{i}:$ & probability mass function for $D_{i}$ \\
\hline$Q:$ & batch order (dispatch) quantity \\
\hline$c:$ & unit production cost \\
\hline$w:$ & unit outsourcing cost \\
\hline & (manufacturer's) unit holding cost \\
\hline $1-\beta$ : & service level at the retailer \\
\hline$z:$ & $\begin{array}{l}\text { the number of production cycles in a capacity cycle, } \\
\qquad z T_{\mathrm{p}}=T_{\mathrm{m}}\end{array}$ \\
\hline
\end{tabular}

Decision variables

$R: \quad$ reorder level at the retailer

$p^{n}$ : number of lots of $Q$ produced in period $n$

$d^{n}$ : number of lots of $Q$ dispatched in period $n$

State variables

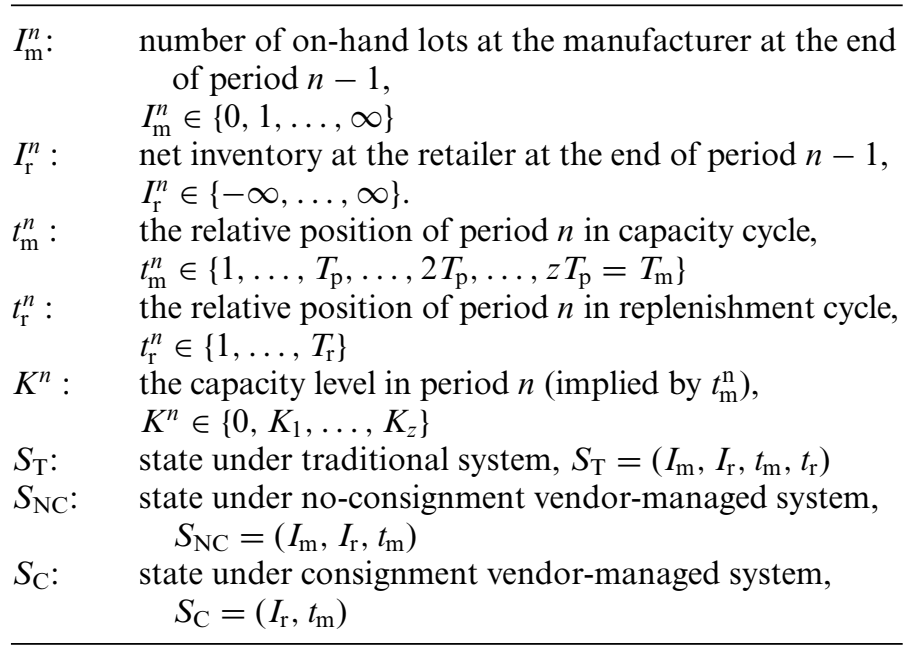

the manufacturer. Similarly, cost information of the manufacturer is not shared with the retailer. Cost information is mutually unavailable.

3. Information on capacity level and end-of-inventory level at the manufacturer is not shared with the retailer.

Therefore, information sharing is asymmetric and partial.

\subsection{Traditional system}

In the traditional model, at the beginning of each period the manufacturer decides on how much to produce and/or to outsource. The manufacturer produces for the retailer in every $T_{\mathrm{p}}$ periods, while the retailer places an order in every $T_{\mathrm{r}}$ periods. $T_{\mathrm{r}}$ is known by the manufacturer. We assume that the fixed cost of transportation is zero under traditional and under vendor-managed systems. We assume that the retailer places orders based on an $(R, n Q)$-type policy, where $R$ is the reorder point that guarantees a specified service level (Zheng and Chen, 1992). Note that due to quantized shipments the analysis would not change under a fixed cost of transportation per batch. The sequence of events under the traditional system is as follows.

1. At the beginning of a period, the manufacturer gives the decision of how many units to produce and/or to outsource, considering the allocated capacity (if allocated capacity is zero, there is no production). If an order is placed by the retailer in the last period of the replenishment cycle, a dispatch is made to the retailer in the first period of the following replenishment cycle. Production, outsourcing, and dispatch lead times are negligible. Therefore, the dispatched quantity is immediately ready at the retailer at the beginning of the replenishment cycle, before any demand is realized at the retailer.

2. Demand is realized at the retailer. If there is enough inventory in stock, the retailer fulfills the demand. If the retailer cannot meet the demand completely, the unmet amount is backordered (at no explicit penalty). If it is the last period of the replenishment cycle, the retailer places an order at the manufacturer (if any), which is a nonnegative integer multiple of $Q$. Otherwise, if it is not the last period, the retailer only passes the demand information to the manufacturer and updates the inventory level.

\subsubsection{Retailer's problem under the traditional system}

The problem of the retailer is to minimize the expected inventory level under a service-level requirement (there is no explicit backorder cost for the retailer). We only consider the operating policies with $(R, n Q)$ structure. In the last period of the replenishment cycle, after the demand is realized, the retailer places an order if the inventory level is equal to or less than the reorder point, $R$. The reorder point, $R$, is the decision variable and $Q$ is assumed to be a parameter.

First, consider the two measures for a given $R$ and $Q$ : (i) expected average inventory level $(\bar{I})$; and (ii) average service level $(1-\beta)$.

The expected average inventory level is expressed as follows:

$$
\bar{I}=\frac{1}{Q} \sum_{i=R+1}^{R+Q} \sum_{j=0}^{i}(i-j) \frac{P_{1}(j)+P_{2}(j)+\cdots+P_{T_{\mathrm{r}}}(j)}{T_{\mathrm{r}}} .
$$

In Equation (1), $P_{1}$ is the probability mass function of single-period demand and $P_{k}, k \in\left\{1, \cdots, T_{\mathrm{r}}\right\}$, is the $k$-convoluted probability mass function (i.e., probability mass function of $k$-period demand). Consider the replenishment cycle $T_{\mathrm{r}}$. Under the quantized ordering policy $(R, n Q)$, at the beginning of each cycle the inventory level at the retailer is $i$ with probability $1 / Q$, where 
$i \in\{R+1, \ldots, R+Q\}$. In the long run, for the first period of the cycle, the expected end-of-period inventory level is $1 / Q \sum_{i=R+1}^{R+Q} \sum_{j=0}^{i}(i-j) P_{1}(j)$. Similarly, for the second period, the expected end-of-period inventory level is $1 / Q \sum_{i=R+1}^{R+Q} \sum_{j=0}^{i}(i-j) P_{2}(j)$, and so on. Since in the long run the probability of being in any period in the replenishment cycle is equal to $1 / T_{\mathrm{r}}$, the time-averaged expected inventory level is expressed as in Equation (1).

We define the average service level as $1-\beta$, where $\beta$ is the expected average fraction of backordered demand per period. Let $\beta_{i}, i=1,2, \ldots, T_{\mathrm{r}}$, denote the expected fraction of backordered demand in the $i$ th period of the replenishment cycle. Then, $\beta_{i}$ would be expressed as follows:

$$
\beta_{i}=\sum_{I_{i}} P\left(I_{i}\right) \frac{E\left[\left(D_{1}-I_{i}\right)^{+}\right]}{E\left[D_{1}\right]}
$$

where $I_{i}$ is the beginning inventory level of the $i$ th period, $P\left(I_{i}\right)$ is the probability that the beginning inventory level is $I_{i}$, and $D_{1}$ is the random variable denoting one-period demand. Then, the expected average fraction of backordered demand, $\beta$, is expressed as

$$
\beta=\frac{\beta_{1}+\beta_{2}+\cdots+\beta_{T_{\mathrm{r}}}}{T_{\mathrm{r}}}
$$

Equivalently, $\beta$ is expressed as follows:

$$
\beta=\frac{1}{Q} \sum_{i=R+1}^{R+Q} \sum_{j=i+1}^{\infty}(j-i) \frac{P_{T_{\mathrm{r}}}(j)}{T_{\mathrm{r}} E\left[D_{1}\right]} .
$$

We limit the operating policy of the retailer to the $(R, n Q)$ policy. Under this policy, to minimize the expected average inventory level in Equation (1), the retailer simply chooses the minimum reorder point that guarantees the desired service level. However, as we analyze below, under quantized ordering the $(R, n Q)$-type policy is not necessarily the optimal policy for the retailer. In other words, even if the optimal reorder point is chosen, the expected inventory level may not be minimized. In Proposition 1, we identify the conditions under which the optimal policy is indeed an $(R, n Q)$-type policy for $T_{\mathrm{r}}=1$. We present the proofs in the Appendix.

Each reorder point implies a service level $(1-\beta)$ and an expected inventory level $(\bar{I})$. Let $S$ be the set of the $\beta$ values implied by all (integer and non-negative) reorder points (note that the elements of set $S$ vary with $Q$ ). For $\beta \in S$, let $R(\beta)$ denote the reorder point that results in the service level of $1-\beta$. (We assume there exists a unique $R(\beta)$ for each $\beta \in S$. Under $T_{\mathrm{r}}=1$ this is possible if $R(\beta)+1 \leq$ $\left.\max \left(D_{1}\right)\right)$.

Proposition 1. Suppose $T_{\mathrm{r}}=1$.

1. For $\beta \in S$, the $(R(\beta), n Q)$ policy is the unique inventory level minimizing policy for the retailer.

2. For $\beta \notin S$, there may exist more than one optimal ordering policy for the retailer, none of which is an $(R, n Q)$ policy.
Proposition 1 implies that for $\beta \in S$ the only policy that achieves the minimum inventory level is a $(R(\beta), n Q)$ policy. We use this result later in Section 4 when analyzing the manufacturer's policy.

\subsubsection{Manufacturer's problem under the traditional system}

We determine the optimal operating policy of the manufacturer under the traditional system. We model the manufacturer's problem as a MDP under average cost criteria as follows.

$$
g(s)=\min _{\delta} \lim _{N \rightarrow \infty} \frac{1}{N} E_{s}^{\delta}\left[\sum_{n=1}^{N} r\left(s_{n}, a_{n}\right)\right],
$$

where $g(s)$ indicates the optimal average cost given that initial state is $s, \delta$ is any Markovian policy (note, the underlying chain is weakly communicating and under average cost criteria an optimal policy exists), $s_{n}$ indicates the state in period $n, a_{n}$ indicates the action in period $n$, and $r\left(s_{n}, a_{n}\right)$ is the (immediate) cost of taking action $a_{n}$ in state $s_{n}$. We define the states under traditional model as $S_{\mathrm{T}}=\left(I_{\mathrm{m}}, I_{\mathrm{r}}, t_{\mathrm{m}}, t_{\mathrm{r}}\right)$ where:

$I_{\mathrm{m}}$ is the number of on-hand lots at the manufacturer at the end of the previous period or at the beginning of the current period. Since capacity in every period is a nonnegative integer multiple of $Q$, without loss of optimality, $I_{\mathrm{m}}$ indicates a non-negative integer multiple of $Q, I_{\mathrm{m}}=$ $\{0,1 \ldots, \infty\}$. If $I_{\mathrm{m}}=2$ for instance, there exists $2 Q$ units in inventory (see the discussion on action space).

$I_{\mathrm{r}}$ is the net inventory at the retailer at the end of the previous period, $I_{\mathrm{r}}=\{-\infty, \ldots, \infty\}$.

$t_{\mathrm{m}}$ denotes the relative position of a period in the capacity cycle, $t_{\mathrm{m}} \in\left\{1, \ldots, T_{\mathrm{m}}\right\}$. We assume $T_{\mathrm{m}}$ implies the following capacity structure, $\left(K_{1}, 0,0, \ldots, 0, K_{2}, 0,0, \ldots, 0, K_{z}, 0,0, \ldots, 0\right)$.

$t_{\mathrm{r}}$ denotes the relative position of a period in the replenishment cycle, $t_{\mathrm{r}} \in\left\{1, \ldots, T_{\mathrm{r}}\right\}$.

In the traditional model, the action is defined only by the production quantity in period $n, p^{n}$. The quantity to be outsourced can already be inferred from the retailer's order quantity at the end of the replenishment cycle. If the order quantity exceeds the amount in stock and the production capacity of the manufacturer, then the remaining quantity should be outsourced. This implies that outsourcing is not an independent decision. Note that outsourcing takes place only at the beginning of the replenishment cycle, since otherwise it will result in additional holding cost. The retailer orders in multiples of $Q$, and capacity available is a multiple of $Q_{i}$; therefore, without loss of optimality, we limit the production quantity in every period to multiples of $Q$ (this implies $I_{\mathrm{m}}$ is a multiple of $Q$ ). The action space in a period is denoted by $p^{n} \in\left\{0,1, \ldots, K^{n}\right\}$, where each value corresponds to the multiple of $Q$. We assume that singleperiod demand is characterized by a discrete probability distribution. 
Next, we define the components of Equation (4) under the traditional model. We define $r(s, a)$, where $s=$ $\left(I_{\mathrm{m}}^{n}, I_{\mathrm{r}}^{n}, t_{\mathrm{m}}^{n}, t_{\mathrm{r}}^{n}\right)$ and $a=\left(p^{n}\right)$, as follows:

$$
r(s, a)=\left\{\begin{array}{cc}
\left(c p^{n}+h\left(I_{\mathrm{m}}^{n}+p^{n}-L\right)^{+}\right. & \\
\left.+w\left(-I_{\mathrm{m}}^{n}-p^{n}+L\right)^{+}\right) Q & \text { if } t_{\mathrm{r}}^{n}=1, \\
\left(c p^{n}+h\left(I_{\mathrm{m}}^{n}+p^{n}\right)\right) Q & \text { if } t_{\mathrm{r}}^{n} \neq 1,
\end{array}\right.
$$

where $L$ denotes the number of lots requested by the retailer at the end of the replenishment cycle, i.e., at the end of period $T_{\mathrm{r}}$. The amount requested is dispatched by the manufacturer in the first period of the replenishment cycle, and is ready at the retailer before the demand is realized. Note that the quantity $L$ is deterministic and can be inferred from $I_{\mathrm{r}}$.

The transition probability $P(j \mid s, a)$ denotes the probability that next state is $j$ given current state is $s$ and action taken is $a$, where $j=\left(I_{\mathrm{m}}^{n+1}, I_{\mathrm{r}}^{n+1}, t_{\mathrm{m}}^{n+1}, t_{r}^{n+1}\right)$. We categorize all possible transitions under the traditional system as follows:

For $t_{\mathrm{r}}^{n} \neq 1$ :

$P(j \mid s, a)=\left\{\begin{array}{cl} & I_{\mathrm{m}}^{n+1}=I_{\mathrm{m}}^{n}+p^{n}, \\ P_{1}\left(I_{\mathrm{r}}^{n}-I_{\mathrm{r}}^{n+1}\right) & \text { if } \begin{array}{l}t_{\mathrm{m}}^{n+1}=t_{\mathrm{m}}^{n}\left(1-1_{\left\{t_{\mathrm{m}}=T_{\mathrm{m}}\right\}}\right)+1, \\ t_{\mathrm{m}}^{n+1}=t_{\mathrm{r}}^{n}\left(1-1_{\left\{t_{\mathrm{r}}=T_{\mathrm{r}}\right\}}\right)+1, \\ \text { otherwise. }\end{array}\end{array}\right.$

where $1_{\left\{t_{\mathrm{m}}=T_{\mathrm{m}}\right\}}$ takes a value of one for the last period of the capacity cycle. $P_{1}\left(I_{\mathrm{r}}^{n}-I_{\mathrm{r}}^{n+1}\right)$ is the probability that single period demand is $I_{\mathrm{r}}^{n}-I_{\mathrm{r}}^{n+1}$.

For $t_{\mathrm{r}}^{n}=1$ :

There are two possibilities. The retailer's order quantity does not exceed the available stock and production quantity, and therefore outsourcing is not necessary. When this is the case, $I_{\mathrm{m}}^{n}+p^{n}-I_{\mathrm{m}}^{n+1}=L$. Otherwise, if outsourcing is necessary, then $I_{\mathrm{m}}^{n+1}=0$. We present the transition probability as follows:

$$
\begin{aligned}
& P(j \mid s, a) \\
& = \begin{cases} & I_{\mathrm{m}}^{n+1}=\left(I_{\mathrm{m}}^{n}+p^{n}-L\right)^{+}, \\
P_{1}\left(I_{\mathrm{r}}^{n}-I_{\mathrm{r}}^{n+1}+L Q\right) & \text { if } \quad t_{\mathrm{m}}^{n+1}=t_{\mathrm{m}}^{n}\left(1-1_{\left\{t_{\mathrm{m}}=T_{\mathrm{m}}\right\}}\right)+1, \\
& t_{\mathrm{r}}^{n+1}=t_{\mathrm{r}}^{n}+1, \\
0 & \text { otherwise. }\end{cases}
\end{aligned}
$$

\subsection{Vendor-managed system}

Under the vendor-managed system, we focus only on the manufacturer's problem since the retailer does not make any decisions. The retailer only requires that her performance measures are as good as those under the traditional system. At the beginning of the production cycle the manufacturer decides on how much to produce and in every period how much to outsource and to dispatch. The dispatched quantity immediately arrives at the retailer, i.e., the lead time of transportation is zero. Note that due to the agreement there does not exist a replenishment cycle. The sequence of events is as follows.

1. At the beginning of a period, the manufacturer gives the decision of how many units to produce (if possible), to outsource, and to dispatch. Inventory status of the manufacturer and the retailer are updated based on the dispatch quantity.

2. The demand is realized at the retailer's site. The inventory status of the retailer is updated and end-of-period holding costs at the manufacturer and at the retailer are incurred.

We analyze the vendor-managed setting under two cases: no-consignment stock and consignment stock.

\subsubsection{No-consignment stock}

Under the no-consignment stock model (VM-NC) the ownership of the stock is transferred to the retailer once the dispatch arrives at the retailer. To be compatible with the traditional system, we assume that under the vendormanaged system the retailer requires the average inventory investment to be as low as, and average service level to be as high as those levels under the traditional system. In other words, the retailer is indifferent between the traditional and the vendor-managed system.

We determine the manufacturer's optimal operating policy under the no-consignment system. We model the manufacturer's problem as a MDP under the average-cost criteria as follows:

$$
\begin{aligned}
& g(s)=\min _{\delta} \lim _{N \rightarrow \infty} \frac{1}{N} E_{s}^{\delta}\left[\sum_{n=1}^{N} r\left(s_{n}, a_{n}\right)\right], \\
& \text { s.t. average inventory level at retailer } \leq \bar{I} \text {, } \\
& \text { service level at retailer } \quad \geq 1-\beta,
\end{aligned}
$$

where $\beta$ is defined as in Equation (3) and $\bar{I}$ as in Equation (1). The constraint on inventory level in Equation (7) reflects the case where the retailer is not willing to pay for inventory investment more than what she pays under the traditional system. In practice, the retailer may require that at least one of the performance measures described by Equation (7) or Equation (8) is improved as a result of the agreement. Hence, the service level specified by $(1-\beta)$ can be regarded as a lower bound, and similarly the limit specified by $\bar{I}$ on the average inventory level under a vendormanaged system can be regarded as an upper bound.

In all our analysis, the right-hand side (RHS) of Equation (7) or Equation (8) is used as is, so that we have comparable cases. Note that it is through these constraints that the availability is ensured at the retailer at the right level of inventory. If instead, the retailer were to operate with min-max bounds on inventory compared to the traditional system, either the service level would be lower or average inventory level would be higher or both. Furthermore, the manufacturer's benefits would decrease due to decreased operational flexibility. 
The state is $S_{\mathrm{NC}}=\left(I_{\mathrm{m}}, I_{\mathrm{r}}, t_{\mathrm{m}}\right)$ where $I_{\mathrm{m}}, I_{\mathrm{r}}$, and $t_{\mathrm{m}}$ are as defined in Table 1. At the beginning of the production cycle the manufacturer decides on how much to produce, $p^{n}$, and in every period how much to outsource, $y^{n}$, and to dispatch, $d^{n}$. The manufacturer produces, outsources, and dispatches in multiples of $Q$, and the capacity available at the beginning of the production cycle is a multiple of $Q$. The action space is denoted as $p^{n} \in\left\{0,1, \ldots, K^{n}\right\}$ and $d^{n} \in\{0,1, \ldots, \infty\}$. Without loss of optimality, we limit the action space to multiples of $Q$. Note that the outsourced quantity at period $n, y^{n}$, is defined by $\left(d^{n}-I_{\mathrm{m}}^{n}-p^{n}\right)^{+}$and is not an (independent) decision variable.

Next, we define the components of Equations (6) to (8). In Equation (6) we define $r(s, a)$, where $s=\left(I_{\mathrm{m}}^{n}, I_{\mathrm{r}}^{n}, t_{\mathrm{m}}^{n}\right)$ and $a=\left(p^{n}, d^{n}\right)$, as follows:

$$
\begin{aligned}
r(s, a)= & \left(c \cdot p^{n}+h\left(I_{\mathrm{m}}^{n}+p^{n}-d^{n}\right)^{+}\right. \\
& \left.+w\left(-I_{\mathrm{m}}^{n}-p^{n}+d^{n}\right)^{+}\right) Q .
\end{aligned}
$$

Note that $L$ in Equation (5) is now a decision variable and is denoted with $d^{n}$. We define transition probabilities $P(j \mid s, a)$ where $j=\left(I_{\mathrm{m}}^{n+1}, I_{\mathrm{r}}^{n+1}, t_{\mathrm{m}}^{n+1}\right)$ as follows:

$$
\begin{aligned}
& P(j \mid s, a) \\
& = \begin{cases}P_{1}\left(I_{\mathrm{r}}^{n}-I_{\mathrm{r}}^{n+1}+d^{n} Q\right) & \text { if } \begin{array}{l}
I_{\mathrm{m}}^{n+1}=\left(I_{\mathrm{m}}^{n}+p^{n}-d^{n}\right)^{+} \\
0
\end{array} \text { otherwise. }\end{cases}
\end{aligned}
$$

The left-hand side (LHS) of Equation (7) reflects the expected inventory level per period at the retailer under the manufacturer's optimal operating policy and is expressed as

$$
\sum_{I_{\mathrm{m}}, t_{\mathrm{m}}} \sum_{i>0} i \pi_{\mathrm{NC}}^{\mathrm{M}}\left(I_{\mathrm{m}}, I_{\mathrm{r}}=i, t_{\mathrm{m}}\right) .
$$

where $\pi_{\mathrm{NC}}^{\mathrm{M}}\left(I_{\mathrm{m}}, I_{\mathrm{m}}=i, t_{\mathrm{m}}\right)$ is the fraction of time spent (or the steady-state probability) in state $\left(I_{\mathrm{m}}, I_{\mathrm{r}}=i, t_{\mathrm{m}}\right)$ under the manufacturer's optimal operating policy under noconsignment system. The LHS of Equation (8) reflects the average service level at the retailer under the manufacturer's optimal operating policy:

$$
\begin{aligned}
& 1-\sum_{I_{\mathrm{m}}, i, t_{\mathrm{m}} i+d(i)>0} \pi_{\mathrm{NC}}^{\mathrm{M}}\left(I_{\mathrm{m}}, I_{\mathrm{r}}=i, t_{\mathrm{m}}\right) \frac{E\left[\left(D_{1}-i-d(i)\right)^{+}\right]}{E\left[D_{1}\right]} \\
& -\sum_{I_{\mathrm{m}}, i, t_{\mathrm{m}} i+d(i) \leq 0} \pi_{\mathrm{NC}}^{\mathrm{M}}\left(I_{\mathrm{m}}, I_{\mathrm{r}}=i, t_{\mathrm{m}}\right) \frac{E\left[D_{1}\right]}{E\left[D_{1}\right]} .
\end{aligned}
$$

In Equation (10) $d(i)$ is the optimal action taken. In the expression note that expected backordered demand is calculated differently if $i+d(i) \leq 0$. When $i+d(i)>0$, the amount of available stock at the retailer before the demand is realized is positive. Then, the expected backordered demand is $E\left[\left(D_{1}-i-d(i)\right)^{+}\right]$. On the other hand, if $i+d(i) \leq 0$, then all demand that occurs in that period should be backordered and the expected backordered demand is $E\left[D_{1}\right]$. For those periods service level is $1-E\left[D_{1}\right] / E\left[D_{1}\right]=0$. Averaging over all periods gives the expression in Equation (10).

Finally, we note that if under optimal dispatch policy the available stock at the retailer before the demand is realized is always positive, then the service level is always positive in all of the periods. When this is the case, the servicelevel expression in Equation (10) can be replaced with the following expression:

$$
\sum_{I_{\mathrm{m}}, t_{\mathrm{m}}} \sum_{i<0} \frac{|i|}{E\left[D_{1}\right]} \pi_{\mathrm{NC}}^{\mathrm{M}}\left(I_{\mathrm{m}}, I_{\mathrm{r}}=i, t_{\mathrm{m}}\right) .
$$

\subsubsection{Consignment stock}

In the consignment stock system (VM-C) the sequence of events is the same as the sequence in the no-consignment system except that the manufacturer owns and manages the inventory at the retailer's site. We determine the manufacturer's optimal operating policy under the consignment system. We model the manufacturer's problem as an MDP under average cost criteria as follows:

$$
\begin{aligned}
& g(s)=\min _{\delta} \lim _{N \rightarrow \infty} \frac{1}{N} E_{s}^{\delta}\left[\sum_{n=1}^{N} r\left(s_{n}, a_{n}\right)\right], \\
& \text { s.t. } \quad \text { service level at retailer } \geq 1-\beta .
\end{aligned}
$$

Note that, since the stocking cost is incurred by the manufacturer there does not exist any constraint on the average inventory level. Furthermore, as we will describe in the following, the reward function, $r(s, a)$, now includes the holding cost at both the manufacturer and the retailer. Observe that Equation (13) is the same as Equation (8).

In the consignment stock model, we assume that the unit holding cost is the same at both the manufacturer's site and the retailer's site. The carrying charge of the inventory at a site is determined by the opportunity cost and risk level at the site. Since stocks at both echelons belong to the same firm (manufacturer), the opportunity costs of the tied-up capital that could be used in some other investment is the same at both sites. Furthermore, the risk levels at both sites are the same, since the manufacturer has a single retailer. If there were multiple retailers, the manufacturer would prefer to keep stock at the upper echelon to minimize the risks and send the items to the lower echelon only when necessary. Due to increased risks, the implied unit holding cost at the lower echelon would be higher. However, in this single-retailer setting keeping the items at the lower echelon rather than at both echelons does not affect the inventory holding cost while improving the service level.

Since the unit holding cost is the same at manufacturer's site and the retailer's site, the manufacturer keeps inventory only at the retailer's site and as a result immediately dispatches whatever it produces and outsources to the retailer's site. Under the consignment stock system the state is defined as $S_{\mathrm{C}}=\left(I_{\mathrm{r}}, t_{\mathrm{m}}\right)$ where $I_{\mathrm{r}}$ and $t_{\mathrm{m}}$ are defined as before, and the actions are only how much to dispatch at 
the beginning of period $n, d^{n} \in\{0,1, \ldots, \infty\}$, where each $d^{n}$ value corresponds to the multiple of $Q$.

We define $r(s, a)$ where $s=\left(I_{\mathrm{r}}^{n}, t_{\mathrm{m}}^{n}\right)$ and $a=\left(d^{n}\right)$ as follows:

$$
\begin{aligned}
r(s, a)= & \left(c \times \min \left\{d^{n}, K^{n}\right\}+w \times \max \left\{d^{n}-K^{n}, 0\right\}\right) Q \\
& +h E\left[\left(I_{\mathrm{r}}^{n}+d^{n} Q-D_{1}\right)^{+}\right] .
\end{aligned}
$$

Note that in $r(s, a)$ the holding cost at the manufacturer's site is not expressed, since stock is kept only at the retailer's site. The transition probabilities are expressed as follows:

$$
\begin{aligned}
& P(j \mid s, a) \\
& = \begin{cases}P_{1}\left(I_{\mathrm{r}}^{n}-I_{\mathrm{r}}^{n+1}+d^{n} Q\right) & \text { if } t_{\mathrm{m}}^{n+1}=t_{\mathrm{m}}^{n}\left(1-1_{\left\{t_{\mathrm{m}}=T_{\mathrm{m}}\right\}}\right)+1, \\
0 & \text { otherwise }\end{cases}
\end{aligned}
$$

The consignment and no-consignment models are different but related. Note that in the MDP the reward functions and the constraints are different (see Equations (6) to (9) and (12) to (14)). However, the two systems are related in that there are parameter settings under which the actions taken under both systems are the same. Note that Equation (7) in the no-consignment model implies a unit holding cost. If the implied holding cost is equal to the manufacturer's holding cost, $h$, then the consignment and noconsignment systems can be regarded as being equivalent in terms of the actions taken. For tighter or more relaxed inventory restrictions the consignment and no-consignment systems are expected to result in different operating policies.

\section{Analysis and comparison of traditional and vendor-managed systems}

In this part, we first provide an analysis on the structural properties of the optimal policy under traditional and no-consignment systems. Then, we compare the cost under a no-consignment system with the cost under a traditional system and the cost under a consignment system. In the remainder of the text, we denote traditional system with TRAD, no-consignment vendor-managed system with VM-NC, and consignment system with VM-C. The proofs are presented in the Appendix.

\subsection{Structural properties of the optimal policy}

We analyze the structural properties of the optimal policy under traditional and under no-consignment systems. We show in Property 1 that the optimal policy under the traditional system is a modified base-stock policy. For the no-consignment system, we discuss how the retailer's optimal policy and the resultant inventory-level and servicelevel constraints affect the manufacturer's optimal policy. In Property 2 we show that under certain conditions, the optimal policy under a no-consignment system is also a modified base-stock policy.
Property 1. Optimal policy of the manufacturer under the traditional system is a modified base-stock policy.

Next, we discuss optimal operating policy of the manufacturer under VM-NC. Under VM-NC the manufacturer decides on how much to produce, outsource and dispatch to the retailer's site. The dispatch policy is subject to the following two constraints.

1. The expected inventory level at the retailer cannot exceed a certain level (as expressed in Equation (7)).

2. The service level at the retailer should satisfy a minimum level (as expressed in Equation (8)).

These constraints make it difficult to characterize the optimal operating policy of the manufacturer. However, as we show in Property 2 under certain conditions the optimal policy of the manufacturer has the rather simple base-stock structure.

To define the manufacturer's policy under VM-NC, we should focus on the retailer's operating policy under the traditional system. In Proposition 1 we show that when $T_{\mathrm{r}}=1$, for $\beta \in S$ there exists a unique optimal policy, which is $(R(\beta), n Q)$. This result leads to the following observation.

Observation 1. For $T_{\mathrm{r}}=1$ and $\beta \in S$ :

1. Under VM-NC the manufacturer's optimal operating policy is defined by a unique dispatch policy. This unique dispatch policy is the same policy as the retailer's order policy under the traditional system, which is $(R(\beta), n Q)$.

2 . The manufacturer's optimal operating policy under VM-NC is independent of $\beta$.

Observation 1 states that for $\beta \in S$, under optimality the only possible dispatch policy of the manufacturer that satisfies constraints (7) and (8) is the retailer's $(R(\beta), n Q)$ policy. In other words, in every period the manufacturer dispatches the minimum amount (in multiples of $Q$ ) to bring the retailer's stock level above $R(\beta)$. Furthermore, the dispatch policy is the same for all $\beta \in S$. The reason for this behavior is that discrete reorder points define $\beta$ and the value of the reorder point does not have an impact on the dispatch policy of the manufacturer. (This structure resembles the one in a base-stock system where the order-up-to point does not affect the quantity ordered every period.) For $\beta \notin S$, multiple dispatch policies may satisfy the constraints (7) and (8). Under optimality the manufacturer may select one of the eligible dispatch policies. Using Observation 1, in Property 2 we provide a characterization of the optimal policy of the manufacturer.

Property 2. For $T_{\mathrm{r}}=1$ and $\beta \in S$, under VM-NC the manufacturer's optimal policy is a modified base-stock policy.

\subsection{Comparison of traditional and vendor-managed systems}

In this section we make two comparisons. First, we compare the no-consignment system with the traditional 
system. Using the structural results of the previous subsection, we show that the cost under the no-consignment system is always lower than or equal to the cost under the traditional system (Property 3 ). We then compare the no-consignment system with the consignment system. In Proposition 4 we show that under certain settings and under certain sufficient conditions the cost of the consignment system is lower than the cost of the no-consignment system.

\subsubsection{Comparison of no-consignment and traditional systems}

Property 3. The cost of the manufacturer under $V M-N C$ is always lower than or equal to the cost under TRAD.

Property 3 states that if under a vendor-managed system stock is not consigned, then the vendor-managed system results in a lower cost than the traditional system; i.e., $V M$ $N C$ is a no-risk case for the manufacturer.

\subsubsection{Comparison of no-consignment and consignment systems}

Although VM-NC is a no-risk case, the cost under VM-NC is not always lower than the cost under VM-C. As we show in the following analysis, under a vendor-managed system consigning the stock may be less costly than not consigning it. In the following, we introduce a specific instance. For this instance, we first obtain a lower bound on the optimal cost under VM-NC (Proposition 2) and an upper bound on the optimal cost under VM-C (Proposition 3). We then identify a set of sufficient conditions that make VM-C less costly than VM-NC (Proposition 4).

Assume that $Q=1$ and that the (single-period) demand, $D$, has the following probability distribution:

$$
P(D)= \begin{cases}1 / 2 & \text { if } D=\mu-1, \\ 1 / 2 & \text { if } D=\mu+1\end{cases}
$$

Assume that capacity per period is $E[D]=\mu$, and $T_{\mathrm{r}}=1$; i.e., under the traditional system the retailer places orders in every period. In the following analysis, we focus on the cases where $\beta \in S$. In this setting since $Q=1$, under the traditional system the retailer operates under the base-stock policy.

Proposition 2. For the instance under consideration:

$$
L B(\mathrm{VM}-\mathrm{NC})=\sqrt{(w-c) h}-\frac{h}{2}+c \mu
$$

is a lower bound on the manufacturer's optimal cost under $V M-N C$.

In the following, we determine an upper bound on the optimal cost of the manufacturer under VM-C (Proposition 3). Under VM-C the manufacturer dispatches whatever he produces and outsources, and the problem under consideration is how much to produce and outsource every period where the decisions are subject to the service-level constraint. We now propose two upper bounds on the optimal cost under VM-C.

Proposition 3. For the instance under consideration:

1. Suppose $w \geq 3 h+c$, and $w$ is such that $\sqrt{(w-c) / h+1} \in \mathbb{Z}^{+}$. Then,

$$
U B(\mathrm{VM}-\mathrm{C})=h\left(\sqrt{\frac{w-c}{h}+1}-\frac{1}{2}\right)+c \mu
$$

is an upper bound on the optimal average cost under $V M-C$.

2. Suppose for $k \geq 1$ and $k \in \mathbb{Z}^{+}, \quad 1-\beta \leq$ $1-\left(\left(k^{2}-k+1\right) / 2 \mu \sqrt{\left((w-c) / h+\left(k^{2}-k+1\right)\right.}\right)$,

$w \geq(5 k+3) h+c$ and $w$ is such that $\sqrt{((w-c) / h)+\left(k^{2}-k+1\right)} \in \mathbb{Z}^{+}$. Then

$$
\begin{aligned}
& U B(\mathrm{VM}-\mathrm{C}) \\
& =h\left(\sqrt{\frac{w-c}{h}+\left(k^{2}-k+1\right)}-\left(k+\frac{1}{2}\right)\right)+c \mu
\end{aligned}
$$

is an upper bound on the optimal average cost under VMC.

Proposition 3 suggests two upper bounds for the optimal cost under VM-C. Part 1 implies more relaxed sufficient conditions for the upper bound and does not require any condition on the service level. When the service level is as high as $100 \%$, the upper bound in part 1 is applicable. The upper bound in part 2 requires tighter sufficient conditions and in return gives a tighter upper bound. Note that $U B(\mathrm{VM}-\mathrm{C})$ in part 2 is decreasing in the parameter $k$. Parameter $k$ denotes how low the inventory level can be set at the retailer. As the service level requirement is lower (i.e., as $\beta$ gets higher) $k$ increases, and $U B(\mathrm{VM}-\mathrm{C})$ decreases.

Using Propositions 2 and 3, in Proposition 4 we present the main result of this subsection.

Proposition 4. Suppose the following conditions are satisfied.

1. $\beta \geq \frac{k^{2}-k+1}{2 \mu \sqrt{((w-c) / h)+\left(k^{2}-k+1\right)}}$,

2. $w>(5 k+3) h+c$,

where $k \geq 2$ and $\sqrt{((w-c) / h)+\left(k^{2}-k+1\right)}, \quad k \in \mathbb{Z}^{+}$. Then, the optimal cost under VM-C is lower than the optimal cost under $V M-N C$.

Proposition 4 compares the no-consignment and consignment models under a deterministic reorder point at the retailer. In practice, firms prefer a fixed operating policy rather than a randomized one due to operational difficulties, even if a randomized policy may yield lower costs. The first condition in the proposition states that if the service-level requirement at the retailer is not high, then consignment stock is preferred. This result is in line with our experimental study where we observed that under $99 \%$ 
service-level consignment stock is never preferred (see Section 5.1). The intuition behind this result is as follows. If the service-level requirement of the retailer is low, then this implies the expected inventory level requirement at the retailer is also low (i.e., RHS of the constraint in Equation (7)). This corresponds to a high "implied unit holding cost" for the stock at the retailer's site. If the implied cost is very high (i.e., if expected inventory level is very low), then the manufacturer simply prefers owning the stock rather than trying to meet the requirement under the no-consignment system. In practice, for items with low implicit stock-out costs, the retailer may allow low service levels. Examples are those items for which the retailer also carries substitutes or products that are not competitive. For these items the inventory requirement imposed by the retailer to the manufacturer would be low, and the manufacturer might prefer consigning the stock to not consigning it. The second condition states that if the outsourcing cost is high, then consigning the stock is preferred. This result also supports our observations from the computational study. Under a high outsourcing cost the manufacturer would prefer to keep high levels of inventory, which is allowed under the consignment stock system but not under the no-consignment system.

Note that our construction assumes $T_{\mathrm{r}}=1$ and $\beta \in S$. Under these assumptions the cost and operating policies under TRAD and under VM-NC are the same. Therefore, the intuition obtained from Proposition 4 could be extended to the comparison of the consignment system with the traditional system. We conclude that the manufacturer prefers VM-C to TRAD when the inventory level constraint is "tight"; i.e., when the operating policy of the retailer imposes an "inflexible" dispatch policy for the manufacturer.

\section{Computational analysis}

We conducted experiments to analyze how the system parameters affect the manufacturer's savings under the vendor-managed system and identified the conditions under which manufacturer is willing to make an agreement. In designing the experiments we kept unit holding cost, and unit production cost, and expected demand per period as constant at $h=1, c=10$, and $E\left[D_{1}\right]=20$. We assumed the lot size was, $Q=5$. We assumed that the capacity cycle was two periods $T_{\mathrm{m}}=2$, production cycle was one period $T_{\mathrm{p}}=1$ and replenishment cycle $T_{\mathrm{r}}$ could be one or two periods. Capacity levels in the capacity cycle were indicated with $K_{1}$ and $K_{2}$. We considered the effect of the following parameters on average cost per period.

1. Total capacity: We assumed the capacity levels were "tight," "medium," or "excessive." Under tight capacity $\bar{K}=\left(K_{1}+K_{2}\right) / 2=E\left[D_{1}\right]=20$, under medium capacity $\bar{K}=25$, and under excessive capacity $\bar{K}=30$.

2. Outsourcing cost: $w=11,15,20$, and 30.
3. Capacity non-stationarity: $\left(K_{1}, K_{2}\right)=(40,0),(30,10)$, $(20,20),(10,30)$, and $(0,40)$.

4. Replenishment cycle: $T_{\mathrm{r}}=1,2$. When $T_{\mathrm{r}}=2$, under the traditional system the retailer places orders in every two periods, whereas she shares the demand and inventory level information in every period. Comparing the traditional system under $T_{\mathrm{r}}=2$ with the vendor-managed system, the manufacturer has a gain in terms of both dispatch quantity and dispatch time (i.e., dispatch frequency) flexibility. In Section 5.1.4 we quantify the benefit of flexibility.

5. Demand coefficient of variation: The demand faced by the retailer was modeled via a discrete distribution. The distributions considered and the corresponding values of the coefficient of variation, $c v$, are as follows: uniform $[11,29](c v=0.28)$, truncated normal $(\mu=20, \sigma=30)$ $(c v=0.57)$, beta $(0.3,0.3)(c v=0.80)$.

6. Service level at the retailer: We assumed service levels of 90,95 , and $99 \%$. When determining the service level at the retailer, we only considered discrete reorder points, and we set the reorder point such that the service level is higher than $90 \%$ (or $95 \%$, or $99 \%$ ). For example, for uniform distributed demand, when $T_{\mathrm{r}}=1$ the retailer's reorder point that gives a service level of at least $90 \%$ is $R=18$ and the service level implied by this reorder point is $90.26 \%$. We present the service levels in Table 2 .

In this section we observe the effect of system parameters on the benefits of vendor-managed systems. We have already shown that the no-consignment system is a no-risk case for the manufacturer, and for $T_{\mathrm{r}}=1$, the cost under TRAD and VM-NC are the same, so when making observations we only compare TRAD and VM-C, unless otherwise stated. However, for certain cases, when we believe that comparison with VM-NC provides further insights we explicitly state this in the discussion.

In the following subsections, we present our results under two main titles: Analysis under Stationary Capacity and Analysis under Non-Stationary Capacity. We used a Linear Programming (LP) model to solve Equations (4) and (12) and average cost per period criteria for the analysis. When LP was used to solve the corresponding MDP problem under VM-C we obtained at most a single randomized action as we have one additional constraint (corresponding to service level). We use the results as obtained. The number of variables of the LP model (Cartesian space of states and actions of the MDP) were 55000 for the traditional

Table 2. Service levels (in percent)

\begin{tabular}{cccccccc}
\hline & \multicolumn{3}{c}{$T=1$} & & \multicolumn{3}{c}{$T=2$} \\
\cline { 2 - 3 } \cline { 7 - 8 } & Uniform & Normal & Beta & & Uniform & Normal & Beta \\
\hline $90 \%$ & 90.26 & 91.06 & 90.41 & & 90.66 & 90.72 & 90.40 \\
$95 \%$ & 95.79 & 95.90 & 95.17 & & 95.18 & 95.49 & 95.42 \\
$99 \%$ & 99.47 & 99.25 & 99.41 & & 99.11 & 99.12 & 99.22 \\
\hline
\end{tabular}


system, and 4060 for the VM-C system. The total number of experiments carried out for the stationary capacity case was 216 , and for the non-stationary case it was 288 . Due to the computational burden associated with Equation (10), we use Equation (11) as a surrogate of the service level at the retailer. Note that Equations (10) and (11) are equivalent if the retailer's initial inventory level in every period is nonnegative. In our experimental setting under the vendormanaged system we expect this to be the case and believe that using Equation (11) instead of Equation (10) has a negligible effect in the results.

\subsection{Analysis under stationary capacity}

We first made a comparison of the vendor-managed system with the traditional system under stationary capacity, when the capacity per period is tight $(\bar{K}=20)$, medium $(\bar{K}=25)$, and excessive $(\bar{K}=30)$. Under stationary capacity, the capacity level over the periods was constant: $\left(K_{1}, K_{2}\right)=(20,20),(25,25)$, and $(30,30)$. Based on the insights obtained in this section, we extended the analysis to the non-stationary capacity.

\subsubsection{Effect of unit outsourcing cost on savings}

We analyze the effect of outsourcing cost $(w)$ on percentage savings under the vendor-managed system $(=100 \times$ (TRADcost - VMScost)/TRADCost) for service levels of 90,95 , and $99 \%$ (we refer to the service levels in Table 2, while we indicate the levels with 90,95 , and $99 \%$ ). As unit outsourcing cost increases, under both the traditional and vendor-managed systems, the average inventory level at the manufacturer increases while the number of units outsourced decreases. However, although the number of outsourced units decreases, the total outsourcing cost increases under both systems. We observe that the increase in inventory level and decrease in number of outsourced units is more drastic under the traditional system compared to the vendor-managed system. As a result of this, the number of units produced in-house increases significantly under the traditional system. We conclude that the traditional system is less robust to the changes in unit outsourcing cost compared to the vendor-managed system. As a result of the changes in the production cost, total outcourcing cost, and inventory holding cost, the cost under TRAD increases at a steeper rate than the cost under VM-C. We observe that the savings under VM-C increase with unit oursourcing cost.

Experimental results for $T_{\mathrm{r}}=1$ support the conclusions derived in Proposition 4: we observe that when the service level is $99 \%$ and the demand coefficient of variance is high, the cost under VM-C is always higher than the cost under TRAD or VM-NC. Otherwise, cost under VM-C can be lower, especially if the outsourcing cost is high. For $T_{\mathrm{r}}=2$, the manufacturer keeps a higher inventory compared to $T_{\mathrm{r}}=1$ under the traditional system, and therefore VM-C can be more beneficial. Finally, as the demand coefficient of variance increases, we observe that the manufacturer's savings under VM-NC increase while savings under VM-C decrease. We conclude that although a higher coefficient of variation helps the manufacturer to manage the operations more effectively, incurring the retailer's inventory holding cost outweighs these savings.

In the overall setting, savings under VM-C can be as high as $5.37 \%$ (when outsourcing cost is high, demand coefficient of variance is low and service level requirement is low) and as low as $-9.80 \%$.

\subsubsection{Effect of the vendor-managed system on capacity utilization}

We analyzed how the capacity utilization changes as the system moves from traditional to vendor-managed system. Capacity utilization is a measure of a manufacturer's ability to meet the demand through in-house production. The unmet demand is outsourced and in this respect the outsourcing cost acts as a lost sales penalty, and capacity utilization reflects the service level provided by the manufacturer. Analysis indicates that capacity utilization is always higher under the vendor-managed system than the traditional system (see Fig. 2). Also, as the unit outsourcing cost increases, the capacity utilization increases. The capacity utilization increases at a higher rate under the traditional system as the unit outsourcing cost increases.

We also analyze the effect of capacity level on the cost under TRAD and VM-C. An increase in capacity level from tight to medium or medium to excessive decreases the cost under both traditional and vendor-managed systems. We observe that how the two systems react to an increase in capacity level slightly differs with respect to the coefficient of variation in demand.

1. When the coefficient of variation of demand is low, under the vendor-managed system the inventory burden on the manufacturer is low. The manufacturer already

\section{Percentage utilization}

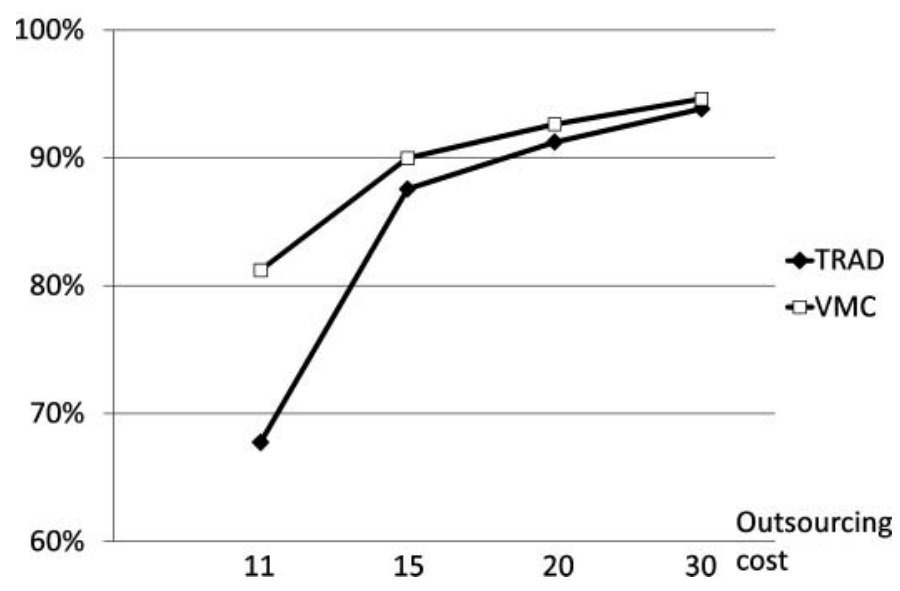

Fig. 2. Effect of outsourcing cost on utilization when the total capacity is tight. 
Cost per period

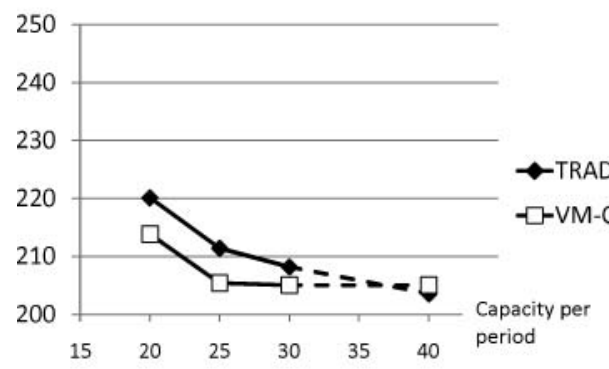

(a)
Cost per period

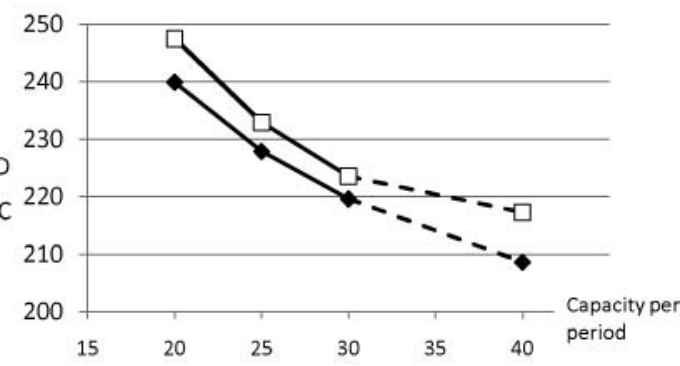

(b)

Fig. 3. Effect of capacity increases on costs under traditional and vendor-managed systems for (a) low demand variance and (b) high demand variance.

uses the capacity effectively, and therefore the benefit of additional capacity is relatively low. Beyond a certain threshold, the increase in capacity does not decrease the cost for the vendor-managed system. On the other hand, under the traditional system, the additional capacity is more beneficial, since additional capacity will help the manufacturer to meet the retailer's orders more effectively. For sufficiently high capacity, we expect that under the traditional system in-house production will be equal to the demand, and no outsourcing cost or holding cost will be incurred. This implies that under a sufficiently high capacity, the cost under the traditional system will be lower than the cost under the vendor-managed system, since under the VM-C there will always be the burden of inventory holding due to the retailer. Therefore, when the coefficient of variation is low, as the capacity level increases, the benefit of the vendor-managed inventory decreases. Figure 3(a) shows the costs under two systems when coefficient of variation is low.

2. When the coefficient of variation of the demand is high, we observe that both the vendor-managed system and the traditional system benefit from an increase in the capacity level. When the capacity level is excessively high, both systems reach a stable level in terms of cost and the cost does not decrease further with an increase in capacity level. We observe that under sufficiently high capacity the average cost under the traditional system can be as low as the total in-house production cost (which is expressed as $c E[D]$ and is the lowest level for the cost), whereas under VM-C the cost consists of the in-house production cost and the inventory cost at the retailer. We conclude that, under sufficiently high capacity, the vendor-managed system is not beneficial. In Fig. 3(b) we show how the costs change with respect to the capacity level when the coefficient of variation is high.

The amount of per period capacity necessary to attain $100 \%$ in-house production is higher under a high coeffi- cient of variation of demand compared to the case where coefficient of variation is low.

\subsubsection{Effect of vendor-managed system on inventory levels}

We compare the expected total inventory level in the system (at the manufacturer and the retailer) and the expected inventory level at the retailer's site under the traditional system and the vendor-managed system. Experimental results show that the expected total inventory level in the system is lower under VM-C.

Property 4. The expected inventory level at the retailer's site has the following properties

1. It is higher under VM-C compared to the traditional system when $T_{\mathrm{r}}=1$,

2. It may or may not be higher under VM-C compared to the traditional system when $T_{\mathrm{r}}=2$.

The inventory level at the retailer's site may or may not be lower under the vendor-managed system depending on how the retailer operates under the traditional system. If the retailer already requires small and frequent replenishments under the traditional system (i.e., if $T_{\mathrm{r}}=1$ ), then the inventory at the retailer's site increases under the vendor-managed system. The reason for this behavior is that under the traditional system the retailer operates with the minimum inventory level for a given service level, since $(R, n Q)$ is the optimal operating policy (see Proposition 1). When the manufacturer manages the retailer's inventory, due to capacity restrictions at the manufacturer, the vendor-managed system corresponds to a constrained system compared to the traditional system. Therefore, the expected inventory level at the retailer is higher.

If under the traditional system the retailer places infrequent and lumpy orders (i.e., when $T_{\mathrm{r}}=2$ ), then under high outsourcing costs and low service levels the inventory level at the retailer's site is higher under VM-C. Under high service levels the inventory level at the retailer's site is lower 
under VM-C. We would like to note that the results may vary if we relax the assumption on the same unit holding cost occuring at both echelons under VM-C. In that case under both consignment and no-consignment stock systems, inventory would be held at both sites and the inventory kept at the retailer's site would be lower. However, there will still be instances under low service levels and high outsourcing cost where the inventory level at the retailer's site is higher under VM-C. Under a low outsourcing cost, we observe that the inventory level at the retailer is always lower under VM-C compared to the inventory level under the traditional system.

\subsubsection{Quantifying dispatch time and dispatch quantity flexibility}

Under the vendor-managed system the manufacturer decides on how much to dispatch in every period depending on the capacity level and demand. In some periods the manufacturer may not make any dispatches whereas at other times he may prefer more frequent dispatches. The vendor-managed system implies a gain in "dispatch time" and "dispatch quantity" flexibility compared to the traditional system. In the following we quantify the benefits due to dispatch quantity flexibility and due to both dispatch time and dispatch quantity flexibility:

5.1.4.1. Measuring dispatch quantity flexibility. To analyze benefits due to dispatch quantity flexibility only, we compare the following two settings: $T_{\mathrm{r}}=2$ under the traditional system, and $T_{\mathrm{r}}=2$ under the no-consignment vendor-managed system. We restrict the dispatch time under the vendor-managed system to one dispatch in two periods. This implies that compared to the traditional system there does not exist an increase in dispatch time flexibility under the vendor-managed system but only an increase in dispatch quantity flexibility. (To obtain the optimal cost of manufacturer under VM-NC with the $T_{\mathrm{r}}=2$ restriction we use the constraint in Equation (10).)

5.1.4.2. Measuring dispatch time and quantity flexibility. To analyze benefits under joint dispatch time and quantity flexibility, we relax the restriction on the dispatch time under the vendor-managed system, we simply compare the traditional system (with $T_{\mathrm{r}}=2$ ) with VM-NC. (To obtain the optimal cost of the manufacturer under VM-NC with no dispatch time restriction we use the constraint in Equation (10).)

Note that when quantifying the benefits of flexibility, we assume that inventory is not consigned.

Figure 4 shows that savings due to dispatch quantity flexibility are high especially when the unit outsourcing cost is high (for this analysis we assumed capacity is tight, $\bar{K}=20$ and demand has a simplified structure such that the demand per period is either 15 or 25 each with probability one-half). Analysis shows that while the dispatch quantity flexibility may or may not decrease the inventory level at
Percentage savings due to quantity and time flexibility

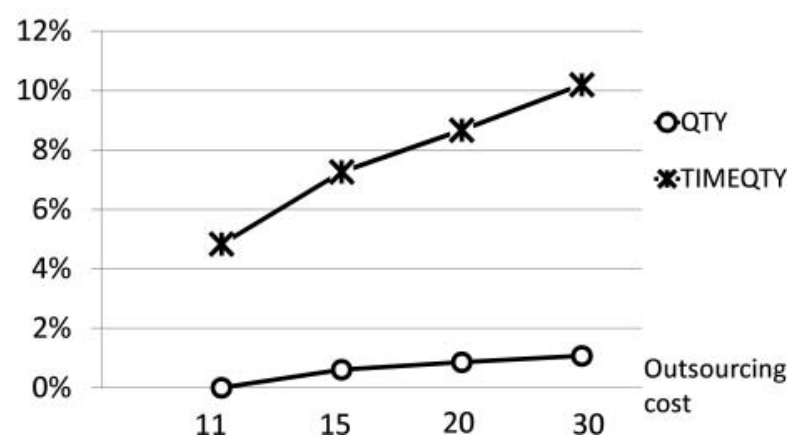

Fig. 4. Effect of dispatch time and dispatch quantity flexibility on savings.

the manufacturer, the additional flexibility due to dispatch frequency decreases the inventory level in the system and significantly increases the savings.

Finally, we note that under the vendor-managed system dispatch time flexibility does not necessarily imply more frequent shipments. Analysis shows that depending on capacity restrictions, under VM-C the manufacturer may prefer less frequent shipments compared to the traditional system, which may result in a lower inventory cost and a lower total cost compared to the traditional system.

\subsection{Analysis under non-stationary capacity}

We now analyze how the costs differ under traditional and vendor-managed systems as the capacity levels change throughout the periods. When the replenishment cycle is one period, under both traditional and vendor-managed systems the lowest cost is incurred when the capacity is stationary at $\left(K_{1}, K_{2}\right)=(20,20)($ Fig. 5(a)). This is expected since the end-demand is stationary. In the two-period replenishment cycle, under the traditional system as more capacity is allocated closer to the replenishment point (which is the first period of the replenishment cycle), the total cost decreases. This is because the manufacturer can use the enddemand information available in the previous period and react accordingly in the replenishment period (Fig. 5(b)).

The analysis under a non-stationary capacity provides insights on how a manufacturer should allocate the capacity under the traditional system versus under the vendor-managed system (of course if possible; i.e., if the manufacturer has the flexibility to change its capacity from one period to another). Under the traditional system the manufacturer would schedule the orders from different customers so that the bulk of production for a certain customer can be realized as the replenishment time for that customer approaches. This may result in erratic orders placed by the manufacturer to the upper echelons. On the other hand, under the vendor-managed system the manufacturer prefers smoothing out the production and dispatch process by allocating the same capacity in every period. Allocating 
Cost per period

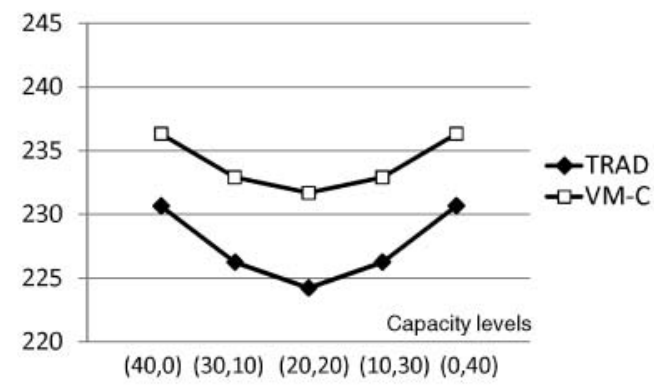

(a)
Cost per period

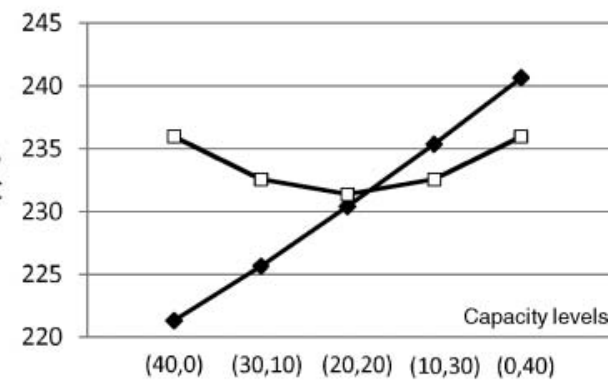

(b)

Fig. 5. Effect of capacity non-stationarity on savings. (a) One-period replenishment cycle and (b) two-period replenishment cycle.

capacity uniformly would result in much less fluctuation in the orders placed by the manufacturer; therefore, the vendor-managed system would also benefit the players in the upper echelons of the supply chain. Note that Lee et al. (1997) specify a similar manufacturing situation to show the bullwhip effect. In our case, we show that capacity management is a useful tool to reduce the bullwhip effect.

The analysis provides further insights on the type of settings under which a manufacturer should or should not prefer the vendor-managed system. If the orders from the retailer are steady, frequent orders with small lot sizes (in our case, when the replenishment cycle is one period), then managing the retailer's inventory would not bring much benefit to the manufacturer, and the cost of consigning the stock may outweigh the benefits (Fig. 5(a)).

On the other hand, if the retailer places the orders infrequently and in large lot sizes (in our case, when the replenishment cycle is two periods), then the manufacturer may or may not benefit from managing the retailer's inventory depending on the flexibility in its operations. When the manufacturer does not have the flexibility to change the capacity (if, for instance, the manufacturer has customers with strict delivery time requirements), experimental results indicate that savings are high (around 1.9\% under the consignment system and $11.6 \%$ under the no-consignment system). The inflexible system is modeled with $\left(K_{1}, K_{2}\right)=(0,40)$ under the vendor-managed system and under the traditional system.

These figures imply that when the manufacturer does not have much control over allocating the capacity to respond to the orders effectively, dispatch quantity and dispatch time flexibility are most useful. However, if the manufacturer can change the capacity to react to the demand patterns, then savings under the vendor-managed system are rather limited. This is because it is already possible to operate the traditional system effectively. Analysis shows that the average savings under the consignment system are $-5.1 \%$, and the savings under the no-consignment system are $4.8 \%$ (here best performances are compared; i.e., averaged cost under $(40,0)$ for the traditional system is compared with the cost under $(20,20)$ for the vendor-managed system). Fully consigning inventory may not be a preferable option if the manufacturer has sufficient flexibility to after its capacity.

\subsection{Managerial insights}

In this section we present the highlights of our analyses. Several of the insights we obtained from the study support and build on the previous findings in the literature, while others reveal new information.

Insight 1. The benefits that the vendor-managed system will bring to the manufacturer depends on the type of the vendormanaged system relationship. There may be benefits beyond sharing demand and inventory information. However, there are a number of cases where VM-C does not yield any additional savings over information sharing as well. Hence, information sharing should be considered as a first step in the relationship with a retailer before going into "risky" vendormanaged relationships. However, the next level of relationship should not necessarily follow; it requires careful evaluation of potential trade-offs.

Insight 1 complements the findings in the literature by assessing the benefit of a vendor-managed system from the manufacturer's perspective. Fry et al. (2001) quantify the effect of VMI on the system-wide cost given that information is already shared and conclude that if certain parameters (such as dispatch quantity or penalty of violating inventory bounds) are not chosen properly, a vendor-managed setting can be more costly for the chain than the traditional setting. We show that if the conditions or the terms of the agreement are tight for the manufacturer, then the vendor-managed system does not bring additional benefit to information sharing.

Insight 2. VM-NC constitutes a no-risk case for the manufacturer. However, there can be cases where VM-C is more profitable than the VM-NC for the manufacturer.

We explicitly compare the no-consignment stock system with the consignment stock system and conclude that if the service-level requirement at the retailer and the coefficient 
of variance for demand are low, and as a result the inventory level has to be tightly kept at a low level, then consigning the stock might be less costly for the manufacturer. In the literature either totally consigned stock or no-consignment stock models are studied and the question of whether the stock should be consigned is unaddressed.

Insight 3. If capacity allocated is sufficiently high, then the manufacturer is less likely to benefit from the vendormanaged system.

Insight 4. Manufacturers usually have the practice of allocating capacity for a product or customer. It turns out that the way to allocate this level "optimally" is not very straightforward; whether the system operates with full information only or under a certain type of the vendormanaged system may lead to different capacity allocation schemes, significantly affecting the performance. If the manufacturer cannot easily change the capacity allocation, i.e., if operating in a rigid system, then it is most likely to benefit the vendor-managed system.

We analyze the interaction of capacity management and the vendor-managed system. Gavirneni et al. (1999) quantify the benefit of information sharing in a supply chain and show that as capacity level increases, the cost savings for the manufacturer increases (with diminishing returns). We observe that the savings of the manufacturer created by the vendor-managed system decreases with an increase in capacity and there exist capacity levels at which the traditional system is less costly. We also analyze the impact of the operating strategy on the capacity allocation decisions. Under the vendor-managed system, the manufacturer prefers smoothing the production decisions by allocating equal capacities in each period, whereas under the traditional system if the orders placed by the retailer are lumpy and intermittent, then capacity allocation is unbalanced and production amounts may fluctuate. Lee et al. (1997) specify a similar manufacturing situation to show that lumpy orders increase the bullwhip effect. We complement the study by showing that the vendor-managed system benefits the upper echelon through smooth production patterns. Our finding is also in line with Disney and Towill (2003). Our analysis on capacity management contributes to the literature by connecting the benefit of vendor-managed systems to capacity management decisions.

Insight 5. The vendor-managed system may or may not decrease the inventory level at the retailer.

Insight 6. The main benefits of the vendor-managed system can be described with "dispatch time" flexibility and "dispatch quantity" flexibility, with the former potentially leading to a reduction in inventory investment in the system. Reduction in inventory investment may occur even if dispatches are less frequent.

Finally, we quantify the benefit of vendor-managed systems in terms of dispatch quantity flexibility and dispatch time flexibility. Cetinkaya and Lee (2000) contrast a traditional system with frequent shipments with a vendormanaged system where shipments are consolidated at the expense of increased inventory levels. Waller et al. (1999) show through a simulation study that vendor-managed inventory may increase the frequency of dispatches to retailers which helps decrease the inventory level. We show that dispatch time flexibility may contribute significantly to the reduction of inventory in the system, and this is not necessarily achieved through increased frequency of the shipments.

\section{Conclusions}

In this study we analyzed a vendor-managed system for a supply chain consisting of a single manufacturer and a single retailer. We modeled the manufacturer effectively, so that the benefits obtained by using a vendor-managed agreement could be analyzed. We assumed that retailer demand information is fully available to the manufacturer and hence only studied the benefits beyond information sharing. We studied both the consignment stock and no-consignment stock systems under the vendor-managed system. We considered the capacity limitation of the manufacturer in our analysis, which turned out to be a very important factor for the manufacturer and analyzed the problem under different capacity allocation schemes to identify the effect of capacity management on benefits. Our main findings are that the vendor-managed system indeed brings benefit to the manufacturer beyond information sharing. The benefits are high, especially under moderate or tight production capacity rather than excessive capacity or under low service-level requirements. Analyses indicated that if the inventory and service-level requirements are too tight, rather than conforming with the specifications, owning the inventory might be less costly for the manufacturer.

Under the vendor-managed system a manufacturer can take a proactive approach in responding to a retailer's demand and thus can increase the capacity utilization. The vendor-managed system provides the manufacturer with both dispatch time and dispatch quantity flexibility, and this flexibility is most valuable when under the traditional system the retailer requests irregular/large shipments rather than small and frequent shipments. We also compared the inventory levels under traditional and vendor-managed systems. Total inventory level in the system is lower; however, the inventory level at the retailer may not be lower. We analyzed the effect of end-demand variability on the savings. A higher variability resulted in higher savings, but the savings were outweighed by the inventory holding costs under the consignment stock model. Finally, we observed the savings under varying capacity allocation schemes. Under the vendor-managed system the manufacturer prefers uniformly allocated capacity, thus helping to reduce the bullwhip effect in the total chain, whereas under 
the traditional system he allocates most of the capacity towards the time of the replenishment. We conclude that consigning inventory under the vendor-managed system may not be a preferable option if the manufacturer has sufficient flexibility in allocating the resources. If the manufacturer has limited or no flexibility, then the vendor-managed system provides the highest benefit.

In the vendor-managed system, we limited the analysis to the two extreme cases, totally consigned stock versus no consignment stock. Between the two extreme cases, in general either the cost of stock at the retailer might be shared by the manufacturer and the retailer or the ownership of inventory can be transferred from the manufacturer to the retailer after some time period between zero and the sales time. Future work will include analysis of a more general ownership model.

\section{Acknowledgements}

Secil Savasaneril acknowledges the research grant provided by Middle East Technical University, BAP-2006-03070003. The authors thank the department editor the anonymous associate editor and two referees for their valuable comments, which helped to improve the article.

\section{References}

Aviv, Y. and Federgruen, A. (1997) Stochastic inventory models with limited production capacity and periodically varying parameters. Probability in Engineering and Informational Sciences, 11, 107-135.

Aviv, Y. and Federgruen, A. (1998) The operational benefits of information sharing and vendor managed inventory (VMI) programs. Unpublished manuscript.

Barnes, E., Dai, J., Deng, S., Down, D., Goh, M., Lau, H.C. and Sharafali, M. (2000) On the strategy of supply hubs for cost reduction and responsiveness. White Paper, School of Industrial and Systems Engineering, Georgia Institute of Technology, Atlanta, Georgia, USA.

Bernstein, F., Chen, F. and Federgruen, A. (2006) Coordinating supply chains with simple pricing schemes: the role of vendor managed inventories. Management Science, 52, 1483-1492.

Cachon, G. and Fisher, M. (1997) Campbell soup's continuous replenishment program: evaluation and enhanced inventory decision rules. Production and Operations Management, 6, 266-276.

Cetinkaya, S. and Lee, C.Y. (2000) Stock replenishment and shipment scheduling for vendor-managed inventory systems. Management Sciencem, 46, 217-232.

Choi, K.S., Dai, J.G. and Song, J.S. (2004) On measuring supplier performance under vendor-managed-inventory programs in capacitated supply chains. Manufacturing \& Service Operations Management, 6, 53-72.

Disney, S. and Towill, D. (2003) The effect of vendor managed inventory (VMI) dynamics on the bullwhip effect in supply chains. International Journal of Production Economics, 85, 199-215.

Dong, Y. and Xu, K. (2002) A supply chain model of vendor managed inventory. Transportation Research Part E: Logistics and Transportation Review, 38, 75-95.

Fishman, C. (2006) The Wal-Mart Effect, Marti Kitabevi Press, Istanbul, Turkey.

Fry, M.J., Kapuscinski, R. and Olsen, T.L. (2001) Coordinating production and delivery under a (z,z)-type vendor-managed inventory contract. Manufacturing \& Service Operations Management, 3, 151173.

Gavirneni, S., Kapuscinski, R. and Tayur, S. (1999) Value of information in capacitated supply chains. Management Science, 45, 16-22.

Hausman, W. (2003) Supplier managed availability, available at http://www.supplychainonline.com (accessed April 8, 2010).

Jaruphongsa, W., Cetinkaya, S. and Lee, C.Y. (2004) Warehouse capacity and delivery time window considerations in dynamic lot-sizing for a simple supply chain. International Journal of Production Economics, 92, 169-180.

Kahn, G. (2002) Made to measure: invisible supplier has Penney's shirts all buttoned up. The Wall Street Journal, September 11, A1.

Kapuscinski, R. and Tayur, S. (1998) A capacitated production-inventory model with periodic demand. Operations Research, 46, 899-911.

Kleywegt, A.J., Nori, V.S. and Savelsberg, M.W.P. (2002) The stochastic inventory routing problem with direct deliveries. Transportation Science, 36, 94-118.

Lee, H.L., Padmanabhan, V. and Whang, S. (1997) Information distortion in a supply chain: the bullwhip effect. Management Science, $\mathbf{4 3}$, $546-558$.

Li, X. and Wang, Q. (2007) Coordination mechanisms of supply chain systems. European Journal of Operational Research, 179, 1-16.

Maxwell, W.L. and Muckstadt, J.A. (1985) Establishing consistent and realistic reorder intervals in production-distribution systems. Operations Research, 33, 1316-1341.

Nagarajan, M. and Rajagopalan, S. (2008) Contracting under vendor managed inventory systems using holding cost subsidies. Production and Operations Management, 17, 200-210.

Nelson, E. and Zimmerman, A. (2000) Minding the store: KimberlyClark keeps Costco in diapers, absorbing costs itself. The Wall Street Journal, September 7, A1.

Puterman, M.L. (1994) Markov Decision Processes: Discrete Stochastic Dynamic Programming, Wiley, New York.

Schenck, J. and McInerney, J. (1998) Applying vendor-managed inventory to the apparel industry. Automatic I.D. News, 14, 36-38.

Shah, J. and Goh, M. (2006) Setting operating policies for supply hubs. International Journal of Production Economics, 100, 239-252.

Valentini, G. and Zavanella, L. (2003) The consignment stock of inventories: industrial case and performance analysis. International Journal of Production Economics, 81-82, 215-224.

Veinott, A.F. (1965) The optimal inventory policy for batch ordering. Operations Research, 13, 424-432.

Waller, M., Johnson, M.E. and Davis, T. (1999) Vendor-managed inventory in the retail supply chain. Journal of Business Logistics, 20, 183-203.

Zheng, Y. and Chen, F. (1992) Inventory policies with quantized ordering. Naval Research Logistics, 39, 285-305.

\section{Appendix}

Proof of Proposition 1. Before starting the proof, we formally state the retailer's problem of minimizing average inventory level as a MDP under average-cost criteria and present the corresponding LP formulation as follows:

$$
\begin{array}{cc}
\text { (P) } \min & \sum_{i>0} i \pi_{i, a}^{\mathrm{R}}, \\
\text { s.t. } \quad \sum_{a} \pi_{j, a}^{\mathrm{R}}-\sum_{i, a} \pi_{i, a}^{\mathrm{R}} P_{j \mid i, a}=0 \quad \forall j, \\
\sum_{i, a} \pi_{i, a}^{\mathrm{R}}=1, \\
\sum_{i<0}|i| \pi_{i, a}^{\mathrm{R}} \\
E\left[D_{1}\right]
\end{array}
$$




$$
\pi_{i, a}^{\mathrm{R}} \geq 0
$$

In (P) $i$ is the end-of-period inventory level at the retailer, $\pi_{i, a}^{\mathrm{R}}$ is steady-state probability that inventory level is $i$ at the retailer, $a$ are actions that are (quantized) order quantities, $1-\beta$ is the required service level, and $P_{j \mid i, a}$ is the transition probability of being in state $j$ in the next period given that current state is $i$, and action is $a$.

Note that $P_{j \mid i, a}=P_{1}(i+a Q-j)$, where $P_{1}$ is defined as in Table 1.

The objective function denotes the expected average endof-period inventory level in steady-state. Equation (A2) preserves the flow balance and Equation (A3) ensures that sum of the steady-state probabilities do not exceed one. Finally, Equation (A4) ensures that the required service level is satisfied.

We now present the proof.

Part 1. We show that for $\beta \in S$ there is a unique solution to problem $(\mathrm{P})$, which is an $(R, n Q)$ policy with reorder parameter $R(\beta)$.

Consider the Lagrange relaxation of $(\mathrm{P})$ :

$$
\begin{gathered}
\mathcal{L}(\lambda)=\min \sum_{i>0} i \pi_{i, a}+\lambda \sum_{i<0}|i| \pi_{i, a}^{\mathrm{R}}-\lambda \beta E\left[D_{1}\right], \\
\text { s.t. } \quad \sum_{a} \pi_{j, a}^{\mathrm{R}}-\sum_{i, a} \pi_{i, a}^{\mathrm{R}} P_{j \mid i, a}=0 \quad \forall j, \\
\sum_{i, a} \pi_{i, a}^{\mathrm{R}}=1, \\
\pi_{i, a}^{\mathrm{R}} \geq 0,
\end{gathered}
$$

where $\lambda>0$ is the Lagrange multiplier. Note that $\mathcal{L}(\lambda)$ is equivalent to the periodic-review stochastic dynamic inventory problem with batch ordering where the overage cost is linear with rate $h=1$ and underage cost is linear with rate $\lambda$. For any $\lambda \in(0, \infty)$ optimal solution for $\mathcal{L}(\lambda)$ is an $(R, n Q)$ policy (Veinott, 1965). It is easy to see that $\exists \lambda$, namely $\lambda_{\beta}$, for which $(R(\beta), n Q)$ is the optimal inventory policy. Note that by definition, the value of the Lagrangian relaxation problem (for any $\lambda$ ) is a lower bound on the optimal value of the main problem $(\mathrm{P})$. Since the optimal solution of $\mathcal{L}\left(\lambda_{\beta}\right)$ makes Equation (A4) an equality and is a feasible solution for $(\mathrm{P})$, we conclude that $\lambda_{\beta}$ is the optimal Lagrange multiplier for $\mathcal{L}(\lambda)$ and $(R(\beta), n Q)$ is the optimal solution for $(\mathrm{P})$. (Note that, for $\mathcal{L}(\lambda), \lambda_{\beta}$ may not be unique.) Furthermore $(R(\beta), n Q)$ is unique, since any other policy (i.e., if reorder point is $R(\beta)+1$ or $R(\beta)-1$ ) would either violate the service-level constraint in Equation (A4) or increase the objective function value in Equation (A1).

Part 2. Through an example, we show that for $\beta \notin S$, there may be more than one solution to $(\mathrm{P})$.

Example 1. Let $Q=1$. Under this assumption the $(R, n Q)$ policy is a base-stock policy with order-up-to level $R+1$. For some $\beta \notin S$, consider the optimal ordering policy. Sup- pose this policy could be a randomized or a deterministic policy. A policy simply states a set of order-up-to levels and the percentage of the time each order-up-to level is reached. Therefore, any policy can be expressed as a convex combination of several order-up-to levels.

Consider the following instance. Let (single-period) demand take values 1,2 , or 3 with probability $1 / 3$. The optimal policy under $\beta=0.1$ is a randomized policy with the following order-up-to levels: at states (i.e., beginning inventory level) -1 and 1 order up to 2 ; at state $0,1 / 5$ of the time order up to $2,4 / 5$ of the time order up to 3 ; at state 2, order up to 3 . Steady-state probabilities under optimal policy are $\pi_{-1}=6 / 30, \pi_{0}=\pi_{1}=10 / 30, \pi_{2}=4 / 30$. Therefore, the optimal policy implies the following: $3 / 5$ of the time order up to $2,2 / 5$ of the time order up to 3 . There may be other policies that correspond to the same scheme. For example, consider the policy: "At all states $3 / 5$ of the time order up to 2 , and $2 / 5$ of the time order up to 3." This policy also yields $\beta=0.1$ and minimizes the inventory level. We conclude that when $\beta \notin S$, there may be multiple optimal policies that are randomized. Note that none of these optimal policies can be a non-randomized $(R, n Q)$ policy since in that case $\beta \in S$.

Proof of Property 1. Under the traditional system, the retailer places orders to the manufacturer at the end of each replenishment cycle. At the beginning of every period (before dispatch) the manufacturer observes the retailer's inventory level, $I_{\mathrm{r}}$. If it is the first period of the replenishment cycle, the manufacturer dispatches the quantity required by the retailer that is, dispatches the minimum amount that will bring the inventory level at the retailer above $R$. The dispatch quantity is simply the "demand" of the manufacturer for the first period of the replenishment cycle, which is "known" due to $I_{\mathrm{r}}$. For the other periods "demand" is zero. Since the dispatch quantity is already implied by $I_{\mathrm{r}}$ there does not exist any uncertainty. This system is equivalent to a production-inventory system where the manufacturer's demand is known with certainty in the current period. If the total production quantity plus the available stock is not sufficient to meet the dispatch, the remaining amount is outsourced. Outsourcing is simply equivalent to a "lost sales" structure where per unit lost sales cost is $w$. Therefore, the manufacturer's system is a periodic-review single-echelon capacitated productioninventory system with Markov-modulated demand, periodically changing capacity levels, and linear overage and "lost sales" costs. The optimal policy of the manufacturer is a modified base-stock policy (see, for example, Aviv and Federgruen (1997), Kapuscinski and Tayur (1998), and Gavirneni et al. (1999)).

Proof of Property 2. To show why Property 2 holds, we argue that the manufacturer's problem under VM$\mathrm{NC}$ is a single-echelon capacitated production-inventory model with Markov-modulated demand and periodically 
changing capacities. Under VM-NC the manufacturer determines the optimal production, outsourcing and dispatch policy. Based on Observation 1 the manufacturer's dispatch policy is already determined as $(R(\beta), n Q)$. Specifically, the manufacturer observes the retailer's end-of-period inventory level and dispatches exactly the minimum amount that brings the inventory level above $R(\beta)$ before demand in the current period is realized at the retailer. The dispatch quantity is simply the "demand" of the manufacturer. The dispatch quantity is inferred from the retailer's inventory level, $I_{\mathrm{r}}$, and therefore does not involve any uncertainty. Similar to the traditional system, this system is equivalent to a production-inventory system where the manufacturer's demand is known with certainty in the current period. Therefore, the manufacturer's system is a periodic-review, single-echelon capacitated productioninventory system with Markov-modulated demand, periodically changing capacity levels, and linear overage and "lost sales" costs. The optimal policy of the manufacturer is a modified base-stock policy.

Finally note that for $\beta \notin S$ the manufacturer's policy is not necessarily a modified base-stock policy since there may exist more than one dispatch policy that results in the same $\beta$ and $\bar{I}(\beta)$. The manufacturer may prefer any of the dispatch policies to minimize the cost and the operating policy can be randomized.

Proof of Property 3. We make the comparison under two cases: (i) for $\beta \in S$ and $T_{\mathrm{r}}=1$ and (ii) for $\beta \notin S$ or $T_{\mathrm{r}} \neq 1$. For $\beta \in S$ and $T_{\mathrm{r}}=1$, Property 2 shows that the dispatch policy of the manufacturer can be characterized as $(R(\beta), n Q)$. Note that the dispatch policy of the manufacturer under TRAD is also $(R(\beta), n Q)$ as imposed by the retailer. From Property 1 and Property 2 both systems operate under modified base-stock policies and the policies are identical. Therefore, the costs are equal.

For $\beta \notin S$ or $T_{\mathrm{r}} \neq 1$, the cost under no consignment is lower than the cost under the traditional system. The reason for this behavior is that, when $\beta \notin S$, the manufacturer can now consider randomized policies and therefore is more flexible in terms of dispatch policies. For $T_{\mathrm{r}} \neq 1$, under the traditional system dispatches are not allowed in any period except the first period of the replenishment cycle. In the no-consignment system, on the other hand, there is no restriction on the dispatch quantity in any period. This corresponds to a more flexible system and therefore the cost under the no-consignment system is lower compared to the traditional system.

Proof of Proposition 2. We make the proof in two steps. In Step 1 for the simple scenario defined, we provide an exact characterization of the optimal Markov-modulated modified base-stock policy under VM-NC (in Lemma A1). Using this characterization, in Step 2 we provide a lower bound on the optimal cost under VM-NC.

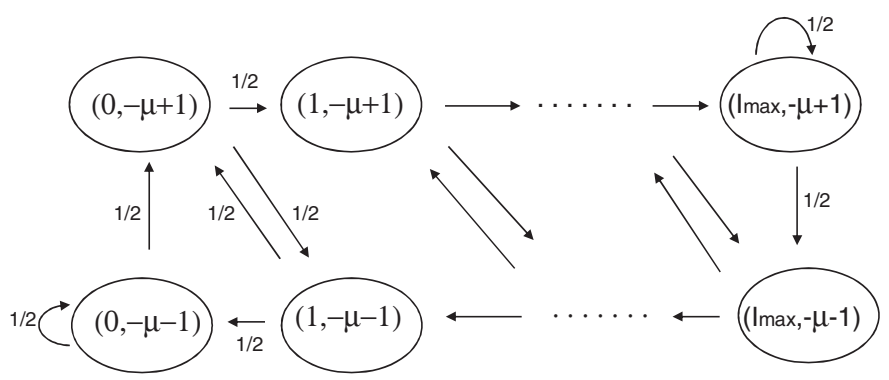

Fig. A1. The transition diagram of the underlying Markov chain of the optimal policy.

Step 1. We assumed $\beta \in S$ and $Q=1$. This implies under optimality there exists a unique deterministic dispatch policy for the manufacturer, which is simply "dispatch the last period's realized demand." The states are $\left(I_{\mathrm{m}}, I_{\mathrm{r}}\right)$ where $I_{\mathrm{m}}$ and $I_{\mathrm{r}}$ are the inventory levels at the beginning of the period at the manufacturer and at the retailer, respectively. If the retailer's demand in the last period is $\mu-1, I_{\mathrm{r}}=$ retailer's base-stock level $-(\mu-1)$. The retailer's base-stock level is directly implied by the service level requirement and is irrelevant to the manufacturer's optimal production and dispatch policy (see Observation 1). For notational simplicity, we ignore "retailer's base-stock level" and simply indicate $I_{\mathrm{r}}$ with $-(\mu-1)$ or $-(\mu+1)$. Lemma A1 characterizes optimal production policy of the manufacturer.

Lemma A1. Under VM-NC the optimal production policy of the manufacturer is as follows (since in our model outsourcing and lost sales are equivalent, we use them interchangeably).

1. If $I_{\mathrm{m}}=0$ and the retailer's demand in the last period is $\mu+1$ (i.e., if $I_{\mathrm{r}}=-\mu-1$ ), produce $\mu$ and outsource one unit (lose the sale of one unit).

2. If $I_{\mathrm{m}}=I_{\max }$ and demand in the last period is $\mu-$ 1 (i.e., if $\left.I_{\mathrm{r}}=-\mu+1\right)$, produce $\mu-1$.

3. Else, produce $\mu$ (i.e., for $0<I_{\mathrm{m}} \leq I_{\max }$ and $I_{\mathrm{r}}=$ $-\mu-1$, or for $0 \leq I_{\mathrm{m}}<I_{\max }$ and $I_{\mathrm{r}}=-\mu+1$ produce $\mu$ ),

where $I_{\max }$ indicates the maximum inventory level at the manufacturer (see Fig. A1).

Proof of Lemma A1. Property 2 states that under VM-NC the optimal production policy is a modified base-stock policy. The modified basestock policy states the following operating policy structure. For states $I_{\mathrm{m}}=0,1, \ldots, k$ produce $\mu$, for $I_{\mathrm{m}}=k+1$ produce $\mu-1$ and decrease the production quantity in unit increments as beginning stock level, $I_{\mathrm{m}}$, increases. For $I_{\mathrm{m}}=0$ producing less than $\mu$ might as well be optimal. Note 
that $k$ might be different for different $I_{\mathrm{r}}$ levels. In the following, for each state, we determine the optimal production quantity (i.e., we determine $k$ for the two $I_{\mathrm{r}}$ levels, $I_{\mathrm{r}}=-\mu+1$ and $\left.I_{\mathrm{r}}=-\mu-1\right)$. We analyze the states $\left(I_{\mathrm{m}},-\mu+1\right)$ and $\left(I_{\mathrm{m}},-\mu-\right.$ 1) separately. The reason for this is that the problem has a Markov-modulated structure and the basestock levels might be different under $I_{\mathrm{r}}=-\mu+1$ and $I_{\mathrm{r}}=-\mu-1$. Note that $I_{\mathrm{m}} \geq 0$.

The optimal production policy under $V M-N C$ is as follows.

1. For states $\left(I_{\mathrm{m}},-\mu+1\right)$ the dispatch quantity is $\mu-1$. We start with the analysis of $I_{\mathrm{m}}=0$. For $(0,-\mu+1)$ the manufacturer may prefer to produce $\mu$ or $\mu-1$. Note that producing $\mu-2$ and outsourcing one unit or outsourcing several units to accumulate stock are more costly actions. Therefore, for $(0,-\mu+1)$ only two actions, produce $\mu$ or $\mu-1$, are under consideration. Note furthermore that outsourcing is not an optimal action in any state $\left(I_{\mathrm{m}},-\mu+1\right)$.

For any $\left(I_{\mathrm{m}},-\mu+1\right)$ if the production quantity is $\mu$, then the next state is $\left(I_{\mathrm{m}}+1,-\mu+1\right)$ or $\left(I_{\mathrm{m}}+1,-\mu-1\right)$ (each with probability onehalf). If, on the other hand, the production quantity is $\mu-1$, then next state is $\left(I_{\mathrm{m}},-\mu+1\right)$ or $\left(I_{\mathrm{m}},-\mu-1\right)$. In other words, the period where the manufacturer decides to produce $\mu-$ 1 under $\left(I_{\mathrm{m}},-\mu+1\right)$ determines a candidate for the maximum stock level under optimal policy, say $I_{\max }$. In point 2 below we show that $I_{\max }$ is indeed the maximum stock level under optimal policy, and in Step 2 we determine the $I_{\max }$ value in terms of problem parameters. Under the optimal policy, for $0 \leq I_{\mathrm{m}}<I_{\max }$ the manufacturer produces $\mu$ and for $I_{\mathrm{m}}=I_{\max }$ the manufacturer produces $\mu-1$ in state $\left(I_{\mathrm{m}},-\mu+1\right)$ (note that $I_{\max }$ can be zero).

2. For states $\left(I_{\mathrm{m}},-\mu-1\right)$ the dispatch quantity is $\mu+1$. We start with the analysis of $I_{\mathrm{m}}=0$. For $I_{\mathrm{m}}=0$ the optimal production quantity is $\mu$ and the remaining one unit is outsourced. Note that producing less than $\mu$ and/or outsourcing more than one unit are more costly actions. Also, for $I_{\mathrm{m}}>0$, outsourcing to accumulate stock is a more costly action. This implies that when the current state is $\left(I_{\mathrm{m}},-\mu-1\right)$, in the next state the $I_{\mathrm{m}}$ level decreases (for $I_{\mathrm{m}}>0$ ). In other words, the candidate $I_{\max }$ in point 1 is indeed the maximum stock level.

Modified base-stock policy states that production quantity is $\mu$ for states $0 \leq I_{\mathrm{m}} \leq k$ and then decreases in unit increments. We would like to determine the optimal value of $k$ (which might as well be zero). First, observe that un$\operatorname{der}\left(I_{\mathrm{m}},-\mu-1\right)$ if the production quantity is $\mu$, then the next state is $\left(I_{\mathrm{m}}-2,-\mu+1\right)$ or
$\left(I_{\mathrm{m}}-2,-\mu+1\right)$ (each with probability onehalf), if the production quantity is $\mu-1$ then next state is $\left(I_{\mathrm{m}}-2,-\mu+1\right)$ or $\left(I_{\mathrm{m}}-2,-\mu+\right.$ 1 ), and so on. In the following, we show that for $0 \leq I_{\mathrm{m}} \leq I_{\max }$ the optimal production quantity is $\mu$.

Define $i$ as the state where the optimal production quantity is $\mu$ for $0 \leq I_{\mathrm{m}} \leq i$ (where $i$ can be anything in $\left.\left\{0,1, \cdots, I_{\max }-1\right\}\right)$. At state $(i+1,-\mu-1)$ possible actions are to produce $\mu$ or $\mu-1$. The optimality equation (under average cost criteria) at state $(i+1,-\mu-1)$ is as follows:

$$
\begin{aligned}
& v(i+1,-\mu-1) \\
& =-g+\min \{\text { produce } \mu, \text { produce } \mu-1\}, \\
& v(i+1,-\mu-1) \\
& =-g+\min \left\{c \mu+(i) h+\frac{1}{2} v(i,-\mu+1)\right. \\
& \quad+\frac{1}{2} v(i,-\mu-1), c(\mu-1)+(i-1) h \\
& \left.\quad+\frac{1}{2} v(i-1,-\mu+1)+\frac{1}{2} v(i-1,-\mu-1)\right\},
\end{aligned}
$$

where $v(i, j)$ is the optimal bias value of starting in state $(i, j)$, and $g$ is the optimal average cost in the MDP (Puterman, 1994).

Now consider the optimality equation at $(i-$ $1,-\mu+1)$. Possible actions are produce $\mu$ or $\mu-1$ :

$$
\begin{aligned}
& v(i-1,-\mu+1) \\
& =-g+\min (\text { produce } \mu, \text { produce } \mu-1), \\
& v(i-1,-\mu+1) \\
& =-g+\min \left\{c \mu+(i) h+\frac{1}{2} v(i,-\mu+1)\right. \\
& \quad+\frac{1}{2} v(i,-\mu-1), c(\mu-1)+(i-1) h \\
& \left.\quad+\frac{1}{2} v(i-1,-\mu+1)+\frac{1}{2} v(i-1,-\mu-1)\right\},
\end{aligned}
$$

Note that the RHS of Equation (A5) and Equation (A6) is the same; therefore, the optimal actions taken at states $(i+1,-\mu-1)$ and $(i-1,-\mu+1)$ must be the same. We have shown in point 1 that for $0 \leq I_{\mathrm{m}}<$ $I_{\max }$ in state $\left(I_{\mathrm{m}},-\mu+1\right)$ the optimal action is to produce $\mu$. We conclude that for $0 \leq$ $i \leq I_{\max }$, the optimal action at state $(i,-\mu-$ $1)$ is to produce $\mu$. This equivalently implies that for $I_{\mathrm{r}}=-\mu-1$, optimal value of $k$ is $I_{\max }$.

The analysis presented in points 1 and 2 completes the proof of Lemma A1. 


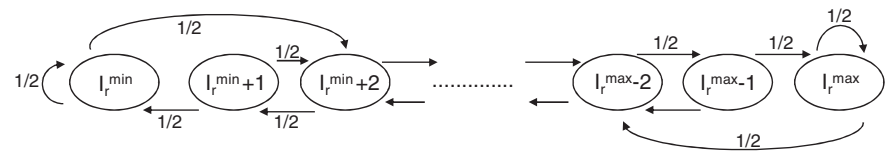

Fig. 2. The transition diagram of the underlying Markov chain under Policy-VMC.

Step 2. Given the manufacturer's optimal policy structure, it is possible to determine the $I_{\max }$ value that minimizes the cost. Under the described optimal policy structure, the corresponding Markov chain implies that the steady-state probability of a state $\left(I_{\mathrm{m}}, I_{\mathrm{r}}\right)$ is

$$
\pi_{N C}^{\mathrm{M}}\left(I_{\mathrm{m}}, I_{\mathrm{r}}\right)=\frac{1}{2 .\left(I_{\max }+1\right)} .
$$

The one-step reward at state $\left(I_{\mathrm{m}}, I_{\mathrm{r}}\right)$ is expressed as follows:

$$
\begin{aligned}
& r\left(I_{\mathrm{m}}, I_{\mathrm{r}}\right) \\
& = \begin{cases}c \mu+w(1) & \text { if } I_{\mathrm{m}}=0, I_{\mathrm{r}}=-\mu-1, \\
c(\mu-1)+h\left(I_{\max }\right) & \text { if } I_{\mathrm{m}}=I_{\max }, I_{\mathrm{r}}=-\mu+1, \\
c \mu+h\left(I_{m}\right) & \text { if } 0<I_{\mathrm{m}} \leq I_{\max } \text { and } \\
& I_{\mathrm{r}}=-\mu-1, \text { or } \\
0 \leq I_{\mathrm{m}} \leq I_{\max } \text { and } \\
I_{\mathrm{r}}=-\mu+1 .\end{cases}
\end{aligned}
$$

Based on the steady-state probabilities and the reward function, we express the average cost under $\mathrm{VM}-\mathrm{NC}$ as

$$
\begin{aligned}
& \operatorname{cost}(\mathrm{VM}-\mathrm{NC}) \\
& =\frac{w(1)+h\left(I_{\max }\right)\left(I_{\max }+1\right)-c(1)}{2\left(I_{\max }+1\right)}+c \mu,
\end{aligned}
$$

where $I_{\max }$ is an integer. Note that $\operatorname{cost}(\mathrm{VM}-\mathrm{NC})$ is convex in $I_{\max }$. The $I_{\max }$ value that minimizes Equation (A7) is

$$
I_{\max }^{*}=\sqrt{\frac{w-c}{h}}-1
$$

In Equation (A8) $I_{\max }^{*}$ can be a real number or an integer. Replacing $I_{\max }$ in Equation (A7) with $I_{\max }^{*}$ gives a lower bound on the optimal average cost under VM-NC:

$$
L B(\mathrm{vM}-\mathrm{NC})^{*}=\sqrt{(w-c) h}-\frac{h}{2}+c \mu .
$$

We write $L B(\mathrm{VM}-\mathrm{NC}) \leq \cos t(\mathrm{VM}-\mathrm{NC})$, since $I_{\max }^{*}$ in Equation (A8) is not necessarily an integer.

Proof of Proposition 3. We consider the following operating policy.

Policy-VMC.

1. For $I_{\mathrm{r}}=I_{\mathrm{r}}^{\min }$, produce (and dispatch) $\mu+1$.

2. For $I_{\mathrm{r}}=I_{\mathrm{r}}^{\max }$, produce (and dispatch) $\mu-1$.
3. Otherwise, for $I_{\mathrm{r}}^{\min }<I_{\mathrm{r}}<I_{\mathrm{r}}^{\max }$, produce (and dispatch) $\mu$.

We assume $I_{\mathrm{r}}^{\max } \geq I_{\mathrm{r}}^{\min }+3$ (i.e., under Policy-VMC there exist at least four states). The proposed policy, Policy-VMC, is not necessarily the optimal policy under VM-C; therefore, the cost implied by this policy will be an upper bound on the optimal cost under VM-C. Note that the transition probabilities for all $I_{\mathrm{r}}$ are one-half. The transition diagram of the underlying Markov chain is presented in Fig. 2.

The steady-state probabilities, $\pi_{\mathrm{C}}^{\mathrm{M}}\left(I_{\mathrm{r}}\right)$, implied by PolicyVMC are as follows:

$\pi_{\mathrm{C}}^{\mathrm{M}}\left(I_{\mathrm{r}}\right)= \begin{cases}\frac{1}{2 \Delta} & \text { for } I_{\mathrm{r}}=I_{\mathrm{r}}^{\min }, I_{\mathrm{r}}^{\min }+1, I_{\mathrm{r}}^{\max }-1, I_{\mathrm{r}}^{\max }, \\ \frac{1}{\Delta} & \text { for } I_{\mathrm{r}}^{\min }+1<I_{\mathrm{r}}<I_{\mathrm{r}}^{\max }-1, \\ 0 & \text { otherwise, }\end{cases}$ where $\Delta=I_{\mathrm{r}}^{\max }-I_{\mathrm{r}}^{\min }-1$. The reward in state $I_{\mathrm{r}}$ is expressed as follows:

$$
r\left(I_{\mathrm{r}}\right)= \begin{cases}c \mu+w(1) & \text { if } I_{\mathrm{r}}=I_{\mathrm{r}}^{\min } \\ c(\mu-1)+h\left(I_{\mathrm{r}}^{\max }\right) & \text { if } I_{\mathrm{r}}=I_{\mathrm{r}}^{\max } \\ c \mu+h\left(I_{\mathrm{r}}\right)^{+} & I_{\mathrm{r}}^{\min }<I_{\mathrm{r}}<I_{\mathrm{r}}^{\max }\end{cases}
$$

Our aim is to determine an upper bound on the optimal average cost under VM-C. Note that in Equation (A10), $I_{\mathrm{r}}^{\max }$ is always positive, since otherwise $\beta \geq 1$. Furthermore, $I_{\mathrm{r}}^{\min }$ is non-positive (since it is already possible to attain $100 \%$ when $I_{\mathrm{r}}^{\min }=0$ ). When determining $I_{\mathrm{r}}^{\min }$ and $\Delta$ we make sure that the service-level constraint in Equation (13), where $\beta \in S$, is satisfied. In other words, the following constraint is satisfied:

$$
\frac{\sum_{i=I_{\mathrm{r}}^{\min }}^{i=0}|i| \pi_{\mathrm{C}}^{\mathrm{M}}\left(I_{\mathrm{r}}=i\right)}{E[D]} \leq \beta .
$$

Based on $r\left(I_{\mathrm{r}}\right)$ and $\pi_{\mathrm{C}}^{\mathrm{M}}\left(I_{\mathrm{r}}\right)$ we write an upper bound on optimal average cost, $U B(\mathrm{VM}-\mathrm{C})$, as follows:

$$
\begin{aligned}
U B(\mathrm{VM}-\mathrm{C})= & \sum_{I_{\mathrm{r}}} r\left(I_{\mathrm{r}}\right) \pi_{\mathrm{C}}^{\mathrm{M}}\left(I_{\mathrm{r}}\right)=w \frac{1}{2 \Delta}+h\left(\frac{1}{\Delta}+\frac{2}{\Delta}+\cdots\right. \\
& \left.+\frac{I_{\mathrm{r}}^{\max }-2}{\Delta}+\frac{I_{\mathrm{r}}^{\max }-1}{2 \Delta}+\frac{I_{\mathrm{r}}^{\max }}{2 \Delta}\right) \\
& -c \frac{1}{2 \Delta}+c \mu .
\end{aligned}
$$

The cost, $U B(\mathrm{VM}-\mathrm{C})$, consists of the cost of production and outsourcing in all states $\left\{I_{\mathrm{r}}^{\min }, \ldots, I_{\mathrm{r}}^{\max }\right\}$ and the cost of holding inventory in states $\left\{1,2, \ldots, I_{\mathrm{r}}^{\max }\right\}$. Replacing $I_{\mathrm{r}}^{\max }$ with $\Delta-\left|I_{\mathrm{r}}^{\min }\right|+1$ :

$$
\begin{aligned}
U B(\mathrm{VM}-\mathrm{C})= & w \frac{1}{2 \Delta}+h\left(\frac{1}{\Delta}+\frac{2}{\Delta}+\cdots+\frac{\Delta-\left|I_{\mathrm{r}}^{\min }\right|-1}{\Delta}\right. \\
& \left.+\frac{\Delta-\left|I_{\mathrm{r}}^{\min }\right|}{2 \Delta}+\frac{\Delta-\left|I_{\mathrm{r}}^{\min }\right|+1}{2 \Delta}\right) \\
& -c \frac{1}{2 \Delta}+c \mu,
\end{aligned}
$$


which is equivalent to

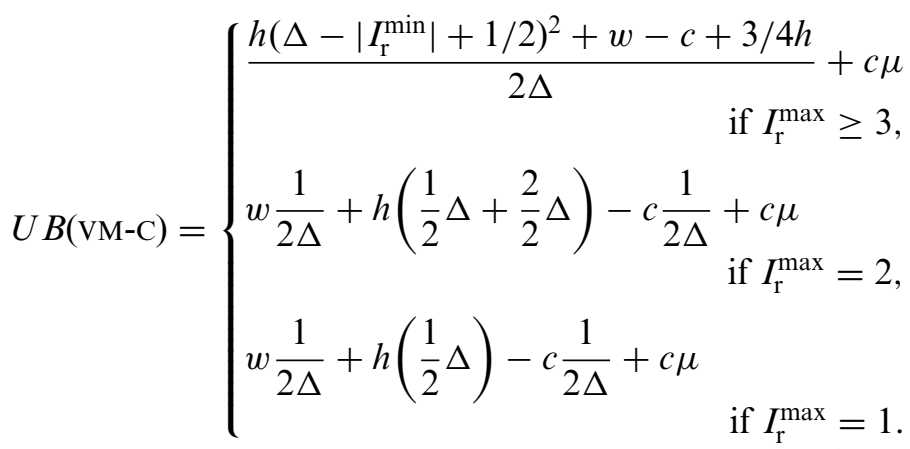

To make the analysis simpler we focus on the case where $I_{\mathrm{r}}^{\max } \geq 3$. This is equivalent to $\Delta-\left|I_{\mathrm{r}}^{\min }\right| \geq 2$. In summary, we make the following assumptions when defining PolicyVMC

A1. $I_{\mathrm{r}}^{\min } \leq 0$.

A2. $\Delta-\left|I_{\mathrm{r}}^{\min }\right| \geq 2$.

From the second-order condition, for $I_{\mathrm{r}}^{\max } \geq 3$ Equation (A12) is convex in $\Delta$. From the first-order condition, the minimizing $\Delta$ is obtained as a function of $I_{\mathrm{r}}^{\min }$ as follows:

$$
\Delta^{*}=\sqrt{\frac{w-c}{h}+\left(\left|I_{\mathrm{r}}^{\min }\right|^{2}-\left|I_{\mathrm{r}}^{\min }\right|+1\right)} .
$$

In order to obtain a "reasonable" upper bound (i.e., an upper bound which is not too relaxed), we consider the $\Delta$ that minimizes Equation (A12). To determine the values $I_{\mathrm{r}}^{\min }$ could take, we make the following observation.

Observation A1. Production and outsourcing cost of the manufacturer is independent of $I_{\mathrm{r}}^{\mathrm{min}}$, and the inventory holding cost decreases as $I_{\mathrm{r}}^{\mathrm{min}}$ decreases.

Observation A1 implies that for a given $\Delta$, as $I_{\mathrm{r}}^{\min }$ decreases the total cost decreases. If there were no servicelevel constraint, to lower the cost one should lower the $I_{\mathrm{r}}^{\min }$ value. However, there is a limit on the lowest value $I_{\mathrm{r}}^{\mathrm{m}}$ in can take when minimizing $U B(\mathrm{VM}-\mathrm{C})$, determined by the service level. Based on Equation (A11) and considering $I_{\mathrm{r}}^{\max } \geq 3$ :

$$
\frac{\left|I_{\mathrm{r}}^{\min }\right|}{2 \Delta}+\frac{\left|I_{\mathrm{r}}^{\min }\right|-1}{2 \Delta}+\frac{\left|I_{\mathrm{r}}^{\min }\right|-2}{\Delta}+\cdots+\frac{1}{\Delta} \leq \beta \mu .
$$

In this expression, for $\beta=0$ (i.e, for $100 \%$ service level) $I_{\mathrm{r}}^{\min }$ should be zero. Otherwise, to be able to set $\left|I_{\mathrm{r}}^{\mathrm{min}}\right|$ as high as $k, \beta$ should satisfy:

$$
\beta \geq \frac{k^{2}-k+1}{2 \mu \Delta} \text { for } k=1, \cdots .
$$

For a required service level, if the $\left|I_{\mathrm{r}}^{\mathrm{min}}\right|$ level is set to its highest possible value, then this would correspond to the lowest possible inventory holding cost under that service level. A limit on how high $\left|I_{\mathrm{r}}^{\min }\right|$ can be set is obtained from Equation (A13). For a given $\left|I_{\mathrm{r}}^{\min }\right|, \Delta^{*}$ minimizes the $U B(\mathrm{VM}-\mathrm{C})$ value. We place $\Delta^{*}$ in Equation (A13) and we suggest two possible upper bound values for optimal average cost under VM-C: $\mathrm{UB} 1$ for $I_{\mathrm{r}}^{\min }=0$, and a generalized upper bound for $\left|I_{\mathrm{r}}^{\mathrm{min}}\right|>0$.

Upper bound 1 (UB1): We set $I_{\mathrm{r}}^{\mathrm{min}}$ to the highest possible value, $I_{\mathrm{r}}^{\min }=0$. Since as $I_{\mathrm{r}}^{\min }$ decreases, $U B(\mathrm{VM}-\mathrm{C})$ decreases, the upper bound obtained under $I_{\mathrm{r}}^{\min }=0$ can be regarded as a "relaxed" upper bound.

For $I_{\mathrm{r}}^{\min }=0$, we obtain:

$$
\Delta^{*}=\sqrt{\frac{w-c}{h}+1} .
$$

From Assumption A2, $\Delta^{*}$ must be greater than or equal to two. This is equivalent to $w \geq 3 h+c$. Furthermore, to guarantee that Equation (A12) is an upper bound, $\Delta^{*}$ must be an integer. Equivalently, we say $w$ should be such that $\Delta^{*}$ is integer-valued.

Placing $I_{\mathrm{r}}^{\min }=0$ and $\Delta^{*}$ in Equation (A12) we obtain the following:

Suppose that $w \in W$, where

$$
W=\left\{w \mid w \geq 3 h+c, \sqrt{\frac{w-c}{h}+1} \in \mathbb{Z}^{+}\right\} .
$$

Then,

$$
U B(\mathrm{VM}-\mathrm{C})=h\left(\sqrt{\frac{w-c}{h}+1}+\frac{1}{2}\right)+c \mu
$$

is an upper bound on the optimal average cost under VM-C. A generalized upper bound: We construct a more general set of conditions for determining an upper bound. Let $I_{\mathrm{r}}^{\min }=k$. For $I_{\mathrm{r}}^{\min }=k$, we obtain:

$$
\Delta^{*}=\sqrt{\frac{w-c}{h}+\left(\left|I_{\mathrm{r}}^{\min }\right|^{2}-\left|I_{\mathrm{r}}^{\min }\right|+1\right)} .
$$

From Assumption A2, $\Delta^{*}$ must be greater than or equal to $\left|I_{\mathrm{r}}^{\min }\right|+2$. This is equivalent to $w \geq\left(5\left|I_{\mathrm{r}}^{\min }\right|+3\right) h+c$. Also, $\Delta^{*}$ must be an integer.

For a required service level $1-\beta$, the highest $\left|I_{\mathrm{r}}^{\min }\right|$ level is obtained as follows:

$$
1-\beta \leq 1-\frac{\left|I_{\mathrm{r}}^{\min }\right|^{2}-\left|I_{\mathrm{r}}^{\min }\right|+1}{2 \mu \sqrt{(w-c / h)+\left|I_{\mathrm{r}}^{\min }\right|^{2}-\left|I_{\mathrm{r}}^{\min }\right|+1}}
$$

Placing $I_{\mathrm{r}}^{\min }$ and $\Delta^{*}$ in Equation (A12) we obtain the following:

Suppose that $w \in W$, where

$$
W=\left\{w \mid w \geq(5 k+3) h+c, \sqrt{\frac{w-c}{h}+\left(k^{2}-k+1\right)} \in \mathbb{Z}^{+}\right\}
$$

and

$$
S L \leq 1-\frac{k^{2}-k+1}{2 \mu \sqrt{(w-c / h)+k^{2}-k+1}} .
$$

Then

$U B(\mathrm{VM}-\mathrm{C})=h\left(\sqrt{\frac{w-c}{h}+k^{2}-k+1}-\left(k-\frac{1}{2}\right)\right)+c \mu$, 
where $k \in \mathbb{Z}^{+}$, is an upper bound on the optimal average cost under $V M-C$.

Proof of Proposition 4. We compare $L B(\mathrm{VM}-\mathrm{NC})$ and $U B(\mathrm{VM}-\mathrm{C})$ and obtain the (sufficient) conditions under which VM-NC results in a higher cost than VM-C. In Proposition 3 we obtain two upper bounds for the optimal average cost of VM-C.

First we compare UB1 with $L B(\mathrm{VM}-\mathrm{NC})$. UB1 may be a reasonable upper bound when the service level requirement is very high. When $I_{\mathrm{r}}^{\min }=0$, the upper bound is expressed as

$$
U B(\mathrm{VM}-\mathrm{C})=h\left(\sqrt{\frac{w-c}{h}+1}+\frac{1}{2}\right)+c \mu .
$$

Comparing this with

$$
L B(\mathrm{VM}-\mathrm{NC})=\sqrt{(w-c) h}-\frac{h}{2}+c \mu,
$$

we obtain that $U B(\mathrm{VM}-\mathrm{C})$ is always higher than the $L B(\mathrm{VM}-\mathrm{NC})$. Similarly, when $I_{\mathrm{r}}^{\min }=1$, we again obtain that $U B(\mathrm{VM}-\mathrm{C})$ is higher than the $L B(\mathrm{VM}-\mathrm{NC})$. Therefore, we conclude that when the service level requirement at the retailer is high, it is less likely that VM-C results in lower cost.

For $I_{\mathrm{r}}^{\min } \geq 2$, under $\Delta^{*}$ the upper bound in Equation (A12) is expressed as:

$$
\begin{aligned}
U B(\mathrm{VM}-\mathrm{C})= & h\left(\sqrt{\left.\frac{w-c}{h}+\left|I_{r}^{\min }\right|^{2}-\left|I_{\mathrm{r}}^{\min }\right|+1\right)}\right. \\
& \left.-\left(\left|I_{\mathrm{r}}^{\min }\right|-\frac{1}{2}\right)\right)+c \mu .
\end{aligned}
$$

Comparing this with $L B(\mathrm{VM}-\mathrm{NC})$, we obtain the following.

$$
\begin{aligned}
& U B(\mathrm{VM}-\mathrm{C})<L B(\mathrm{VMNC}), \\
& h\left(\sqrt{\frac{w-c}{h}+\left(\left|I_{\mathrm{r}}^{\min }\right|^{2}-\left|I_{\mathrm{r}}^{\min }\right|+1\right)}-\left(\left|I_{\mathrm{r}}^{\min }\right|-\frac{1}{2}\right)\right) \\
& \quad<h\left(\sqrt{\frac{w-c}{h}}-\frac{1}{2}\right), \\
& \left|I_{\mathrm{r}}^{\min }\right|<2 \sqrt{\frac{w-c}{h}}\left(\left|I_{\mathrm{r}}^{\min }\right|-1\right) .
\end{aligned}
$$

As $\left|I_{\mathrm{r}}^{\min }\right|$ increases it is more likely that $\mathrm{VM}-\mathrm{C}$ yields lower cost. For $I_{\mathrm{r}}^{\min }=k$,

$$
w>\frac{1}{4}\left(\frac{k}{k-1}\right)^{2} h+c
$$

is a sufficient condition for $U B(\mathrm{VM}-\mathrm{C})<L B(\mathrm{VM}-\mathrm{NC})$. Note that in Proposition 3 we obtained $w \geq(5 k+3) h+$ $c$ for $k \geq 1$ as a tighter condition than

$$
w>\frac{1}{4}\left(\frac{k}{k-1}\right)^{2} h+c
$$

Therefore, we only consider $w \geq(5 k+3) h+c$.

We summarize the sufficient conditions for preferring VM-C over VM-NC as follows.

$$
\text { 1. } S L \leq 1-\frac{k^{2}-k+1}{2 \mu \sqrt{(w-c / h)+k^{2}-k+1}}
$$

2. $w \geq(5 k+3) h+c$.

3. $w$ is such that $\sqrt{(w-c / h)+k^{2}-k+1}$ is integervalued.

4. $k \geq 2$.

We conclude that when the sufficient conditions are satisfied, the optimal cost under VM-C is lower than the optimal cost under VM-NC.

\section{Biographies}

Seçil Savaşaneril is an Assistant Professor in the Department of Industrial Engineering at Middle East Technical University. Her research interests include supply chain management and collaboration and optimal control of stochastic systems. She received a B.Sc. from Middle East Technical University and M.Sc. and Ph.D. in Industrial Engineering from the Georgia Institute of Technology.

Nesim K. Erkip is a Professor of Industrial Engineering at Bilkent University, Ankara, Turkey. His main research interests are in multi-echelon inventory theory, issues in supply chain management, and operations management. 